\title{
Ebusus Phoenissa et Poena. La isla de Ibiza en época fenicio-púnica
}

\author{
Benjamí Costa y Jordi H. Fernández
}

\begin{abstract}
RESUMEN
Los resultados de las investigaciones arqueológicas realizadas en Ibiza en los últimos veinticinco años, permiten concluir que el proceso de colonización de la isla se desarrolló en dos fases claramente diferenciadas: El primer establecimiento semita fue realizado en el siglo vil a.C. por fenicios occidentales y se vincula a la expansión del círculo colonial del Estrecho de Gibraltar. El segundo, supuso el asentamiento en Ibiza de contingentes púnicos de población, desde fines del siglo vi y sobre todo durante el $\mathrm{V}$ a.C.. Este hecho, junto al desarrollo de la población existente, hizo posible la ocupación de toda la isla que, además de ser un importante puerto comercial, pasa a ser también un centro productor y exportador, a la vez que quedará vinculada al ámbito púnico liderado por Cartago. De esta manera, en la isla se forjará una formación social púnico-ebusitana que, en los siglos siguientes, experimentará un notable

\section{ABSTRACT}

The archaeological research carried out in lbiza in the last twenty five years allows us to conclude that the process of the island's colonization in Antiquity took place in two clearly different phases: The first semitic settlement was undertaken by western Phoenicians and was related to the expansion of the colonial circle of the Straits of Gibraltar in the 7th century B.C. The second one, from the end of the 6 th century and throughout the 5th century B.C., gave rise to the establishment in lbiza of new groups of Punic settlers. This fact, together with the growth of the existing population, made possible an important urban development and the occupation of the whole of the island. In this way, Ibiza, besides being a trading port, became also an important producer and exporter of its own goods, while at the same time becoming integrated into the Punic circle where Carthage played a leadership role. Thus, a Punic-ebusitan society was formed in the island, which flourished in the following centuries.
\end{abstract}


desarrollo. Tras la segunda Guerra Púnica, Ibiza quedará bajo dominio romano como ciudad federada, iniciando entonces un largo proceso evolutivo, que la llevará a integrarse plenamente en el Imperio, como municipio latino, en el siglo I d.C.

\section{PALABRAS CLAVE}

Ibiza, fenicios, púnicos, romanización.
After the second Punic War, the island was left under Roman's domination as a federated town, at which point began a long process of transformation which lead Ibiza to its full integration in the Roman Empire, as a latin municipality, in the 1st century A.D.

KEY WORDS

Ibiza, Phoenicians, Punics, romanization.

\section{INTRODUCCIÓN}

La investigación fenicio-púnica cuenta en lbiza con una larga tradición de estudios, que en ciertos momentos ha ido incluso en detrimento de la de otros períodos de la Historia de las Pitiusas. Pero, a pesar de una trayectoria de más de noventa años de investigaciones (Costa y Fernández, 1995 b), en la que en alguna ocasión llegó a ser un hito destacado en el conjunto de la investigación española (López Castro, 1992 a), y aún con los notables avances en las últimas décadas (Gómez, 1988; Costa y Fernández, 1995 b), que hacen que ésta sea la época mejor conocida de nuestra historia antigua, son todavía numerosas las incógnitas que quedan por resolver.

La única fuente que nos proporciona alguna información referente a la fundación de Ibiza es el reiteradamente citado texto de Diodoro Sículo $(\mathrm{V}, 16,2-3)$ que, siguiendo a Timeo de Taormina, afirma literalmente

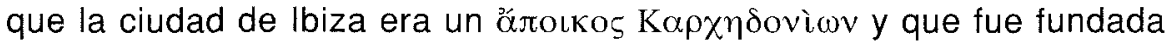
ciento sesenta años después que Cartago. A partir de aquí, tradicionalmente se había interpretado que la fundación de Ibiza habría tenido lugar en el 654-653 a.C., y que este hecho habría sido la primera acción que marcaría el inicio de la expansión mediterránea de la capital norteafricana.

Pero, en primer lugar, el texto de Diodoro admite lecturas bien distintas de la tradicional (Ramón, 1981 a: 25-26; Barceló, 1985: 271-282; ídem, 1988: 127-130; Costa, Fernández y Gómez, 1991: 759-760; Costa 1994: 89-97), pues dice exactamente lo que dice, y no lo que se entendió que decía partiendo de un planteamiento interpretativo que atribuía a Cartago un expansionismo imperialista, en su afán de cerrar el paso al 
comercio griego, cuya primera prueba sería la fundación de Ibiza (García y Bellido, 1952). Y, hoy por hoy, este planteamiento está seriamente cuestionado (Whittaker, 1978; G. Wagner, 1983, 1984, 1986 , 1989 y 1994; López Castro, 1991 a y 1991 b). En segundo lugar, la evidencia arqueológica confirma, en líneas generales, la fecha señalada por Diodoro, al ofrecer unos contextos de poblamiento estable mayoritariamente fechables a mediados, y sobre todo en la segunda mitad, del siglo vII a.C. Sin embargo, niega a Cartago el protagonismo del primer asentamiento, al tiempo que incluye lbiza en el marco de la expansión fenicia en el Mediterráneo Occidental, pues tanto las características de los yacimientos como de los materiales exhumados remiten al ámbito fenicio occidental (Ramón, 1981 a, 1982 a, 1984, 1985 a, 1991 a; Fernández, Gómez y Gurrea, 1984; Costa, 1986, 1988 y 1991; Costa y Fernández, 1988, 1990 a, 1992 y 1993 a; Costa, Fernández y Gómez, 1991; Gómez, 1991 a, 1992, 1995 y 1996; Gómez et alii, 1990). Los resultados, por tanto, ratifican las propuestas iniciales de Maluquer (1969), que fue el primero en desvincular lbiza de la política expansionista de Cartago, y de Baqués (1975), a partir de la datación de los escarabeos más antiguos.

Así pues, aún cuando algunos autores como G. Wagner y Alvar (1989), de Frutos Reyes (1991: 77-78), Gras, Rouillard y Teixidor (1991: 247), o Fantar (1993, t. 2: 57-59; ídem, 1994: 89) entre otros, continúan aceptando con diversos argumentos la interpretación tradicional del texto de Diodoro y considerando Ibiza como una fundación de Cartago, existe un consenso cada vez más amplio de autores que defendemos que el proceso colonial ibicenco se desarrolló en dos fases: una inicial fenicia, vinculada a la expansión de la red colonial feniciooccidental, que se data - al menos de forma clara - en la segunda mitad del siglo VII a.C., y una segunda corriente colonial procedente del área púnica centro-mediterránea, con toda probabilidad de la misma Cartago y de su área de influencia, cuyos testimonios comienzan a hacerse evidentes a partir del último tercio del siglo vi a.C. (Barceló, 1986 y 1988; Costa y Fernández, 1988, 1990, 1992 y 1993 a; Costa, Fernández y Gómez, 1991; Costa, 1994; Gómez et alii, 1990; Ramón, 1982 a; idem, 1985 a). Esta panorámica de la Ibiza arcaica, que se ha construido a partir de los datos arqueológicos y la crítica a la única fuente literaria, en los últimos años ha tenido una creciente aceptación entre una buena parte de los investigadores (Corzo, 1988: 106; Moscati, 1989: 221-223; ídem, 1994: 51-52; Aubet, 1987: 275; Eadem, 1993: 25-26; Alvar, 1995: 126; etc), algunos rectificando o matizando sus afirmaciones anteriores. 

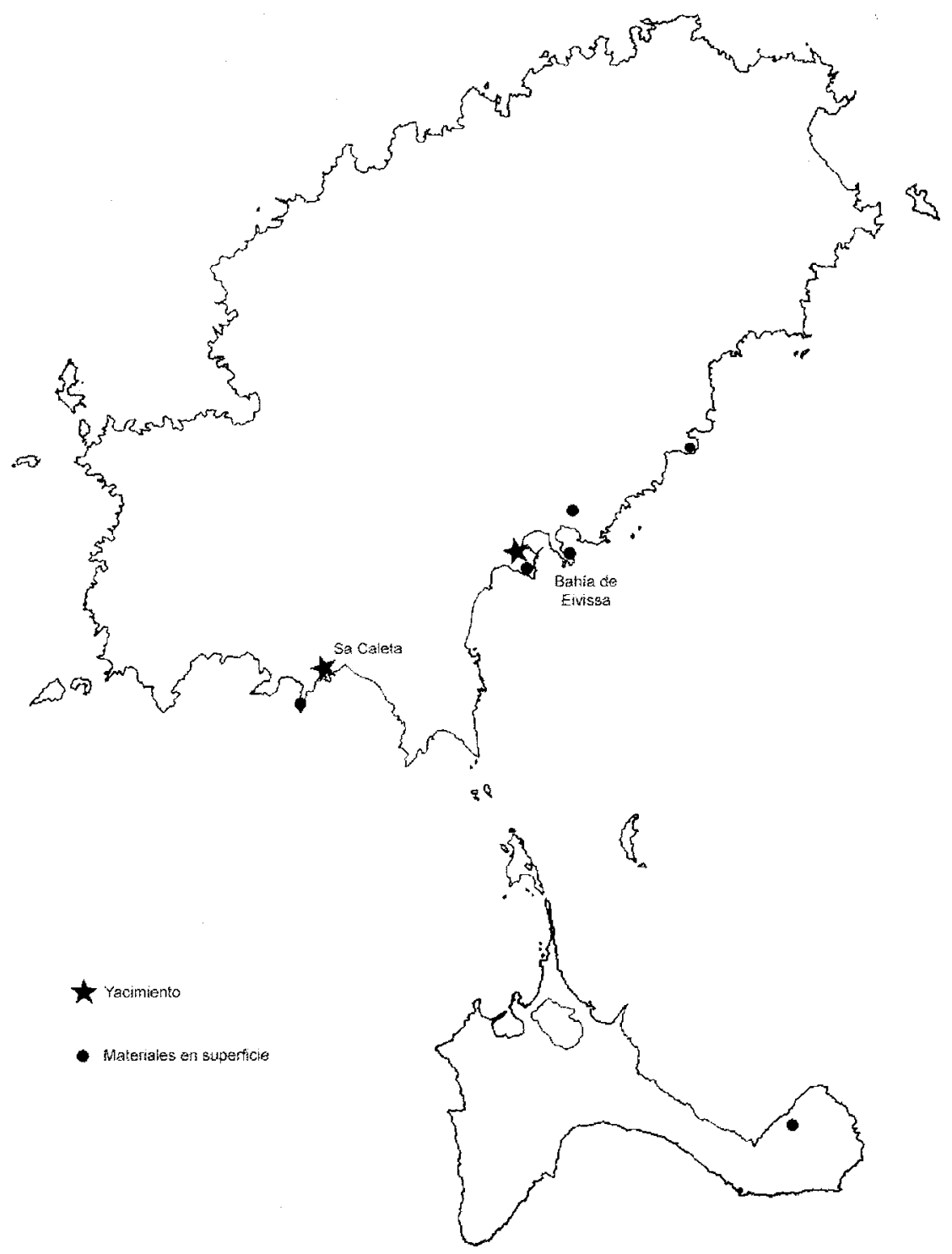

Figura 1. Mapa de las islas Pitiusas con los principales hallazgos fenicios. 


\section{EL ASENTAMIENTO FENICIO (CIRCA 625-525 A.C.)}

Ya desde el primer momento en que se planteó una presencia fenicia en Ibiza, ésta se vinculó a una progresión del comercio fenicio por el litoral oriental de la Península, principalmente en Cataluña, desde la desembocadura del Ebro hasta las costas Narbonenses (Maluquer, 1969; Arteaga, Padró y Sanmartí, 1978). Precisamente, una de las novedades más significativas de la investigación en los últimos años es la constatación, cada vez con mayores argumentos, de que la presencia fenicia en toda la fachada mediterránea peninsular es más antigua de lo que hasta no hace mucho se venía considerando, pudiendo hablarse ya de la existencia de testimonios materiales fenicios probablemente del siglo VIII a.C. en algunos puntos de Cataluña (Asensio et alii, 1996). Sin embargo, es en el Sudeste, principalmente en la provincia de Alicante, donde han sido más impresionantes los hallazgos, pues éstos no sólo permiten plantear una presencia de productos de importación fenicios en contextos indígenas, como hace ya más de veinticinco años se constató en Vinarragell (Mesado, 1974) y los Saladares (Arteaga y Serna, 1975), y luego en otros muchos lugares. En Crevillente, desde los años ochenta, las evidencias permiten afirmar la existencia de un grupo de artesanos semitas conviviendo con los indígenas, en un barrio situado en la periferia del núcleo del Bronce Final de la Peña Negra, que ahora adquiere proporciones urbanas (González, 1993). Pero, además, las recientes excavaciones en la desembocadura del río Segura están aportando importantes resultados, tanto bajo el establecimiento fenicio existente bajo el ribat islámico de Guardamar del Segura (González, 1991), como en el Cabezo Pequeño del Estaño (García Menárguez, 1994). E incluso, en el caso de la Fonteta, los hallazgos llevan a sus excavadores a plantear que el establecimiento fenicio de este lugar, cuyo inicio se situa en pleno siglo vilI a.C., se convirtió en una verdadera ciudad de cerca de $8 \mathrm{Ha}$. de extensión, la cual, en su última fase, se rodeó de una imponente y compleja cinta muraria, de hasta $7 \mathrm{~m}$ de espesor, con un bastión cuadrangular (González, García y Ruiz, 1997). De este modo, hoy queda demostrado que el «litoral fenicio» no terminaba en la desembocadura del Almanzora, sino que, como mínimo desde fines del siglo vIII a.C., desde Gibraltrar alcanzaba la provincia de Alicante, llegando al menos hasta la desembocadura del Segura (Aubet, 1995: 231).

Por todo ello, no es de extrañar que recientemente se haya planteado una posible presencia fenicia en Ibiza ya en el siglo VIII a.C., aunque atendiendo a la parquedad de las evidencias existentes, por el momento tan sólo se hable de "frecuentaciones" (Ramón, 1996: 412). Las pruebas materiales, hoy por hoy, las constituyen solamente algunos fragmentos de 
ánforas fenicias T-10.1.1.1 y T-3.1.1.1 (Ramón, 1995 a), fechables a fines del siglo VIII y primeros decenios del VII a.C., aparecidos en el yacimiento de sa Caleta (figura 3,1 y 2), aunque no en contexto cerrado (Ramón, 1996: 408, figura 4).

En cualquier caso, y dejando siempre abierta la puerta a lo que puedan deparar futuros hallazgos, lo que con los datos existentes hoy en día podemos afirmar es que el asentamiento permanente en lbiza, parece que tuvo lugar a mediados o ya en la segunda mitad del siglo vII a.C. Teniendo en cuenta que algunas dataciones de C-14 obtenidas en Morro de Mezquitilla ofrecen fechas de fines del siglo IX a.C. (Schubart, 1982: 81-82; ídem, 1983: 130), y que la existencia de diversas fundaciones fenicias es segura a mediados del siglo VIII (Aubet, 1987), el establecimiento definitivo en Ibiza parece que tuvo lugar más de un siglo después de la fundación de los primeros enclaves del "círculo del estrecho de Gibraltar». Ello coincidiría con un momento de máximo crecimiento y desarrollo de los centros andaluces, particularmente visible en Toscanos (Aubet, 1987: 266), que hace años el profesor Arteaga (1987: 219) calificaba como «gran apogeo fenicio occidental». Crecimiento que se produce en el marco de pleno desarrollo de un comercio colonial estatalmente controlado y dirigido a la obtención de materias primas y productos diversos, mediante la incentivación de los sistemas productivos y las redes de intercambio indígenas (Aubet, 1993; Eadem, 1995), aunque no faltan interpretaciones que plantean también otros móviles, e incluso una colonización territorial de finalidad agrícola (Alvar y G. Wagner, 1988; G. Wagner y Alvar, 1989).

Este desarrollo del «círculo del Estrecho» durante el siglo vII a.C., que dió lugar a la fundación de nuevos enclaves en la zona andaluza - como el Cerro del Prado (Ulreich et alii, 1990), la Loma del Aeropuerto (Aubet, 1992) o el Cabecico de Parra (López Castro, San Martín y Escoriza, 198788)-, junto con el incremento de la demanda de materias primas en los mercados mediterráneos, provocaría la necesidad de reorientar sus estrategias mediante una expansión del área de su actividad económica, con la consiguiente ampliación y diversificación de las áreas de captación. En este contexto podríamos situar el establecimiento permanente en Ibiza que, siguiendo un modelo propuesto hace años por O. Arteaga (1987) y más recientemente por $M^{\mathrm{a}}$. $E$. Aubet (1995), podría considerarse como el establecimiento de un enclave «secundario» a partir de otro primario más antiguo (Costa y Fernández, en prensa).

Lógicamente, el asentamiento en Ibiza no es un hecho aislado. En el mismo marco se situarían la potenciación de los intercambios con la Andalucía interior, así como nuevos establecimientos en zonas periféri- 
cas, que aparentemente hasta entonces eran marginales, como el litoral atlántico de Marruecos (Jodin, 1966), las costas portuguesas (Tavares et alii, 1993), o el litoral oranés (Vuillemot, 1965). En el caso de Ibiza, como avanzara el profesor Maluquer hace casi treinta años (1969), su papel fundamental -al menos uno de ellos - sería proyectar el comercio fenicio hacia los mercados de la zona catalana y del Golfo de León (Aubet, 1995: 237). Los hallazgos en la última década, principalmente en el bajo Ebro (Sanmartí, 1991; Mascort, Sanmartí y Santacana, 1991; Alaminos et alii, 1991; Asensio et alii, 1996), junto con los anteriormente conocidos en éstas y otras comarcas catalanas (Maluquer, 1969; Arteaga, Padró y Sanmartí, 1978; ídem, 1986), rosellonesas y languedocienses (Jully, 1983), ilustran sobre el alcance, productos y mecanismos de este comercio fenicio, principalmente desarrollado desde lbiza, dirigido hacia las comunidades del Hierro en las costas de Cataluña y Galia Narbonense (Aubet, 1993; Ramón, 1996). Por otro lado, entre los factores que pudieron favorecer el asentamiento fenicio en lbiza hemos de valorar también la posición estratégica de la isla en las rutas mediterráneas, tanto por los contactos Este-Oeste, especialmente en el tramo comprendido entre Mozia y la península Ibérica, como sobre todo por los de Sur-Norte, es decir, desde Gibraltar y la costa andaluza hasta el Golfo de León (Aubet, 1987: 170-171; Ruiz de Arbulo, 1990: 103-106).

Otro importante aspecto a considerar es el de la situación de la isla a la llegada de los colonizadores fenicios. Ésta, evidentemente, carecería de las importantes comunidades indígenas de Mallorca y de Menorca. Sin embargo, y aún a pesar de las enormes lagunas en el registro arqueológico actual, no compartimos en absoluto la vieja teoría de que la isla se encontraba práctica o totalmente deshabitada a la llegada de los primeros colonos semitas (García y Bellido, 1952: 339; Almagro, 1960: 656), que en la última década ha vuelto a ser planteada (Gómez y San Nicolás, 1988: 222-223; Gómez, 1993: 83; ídem, 1995: 452). Como ya señalamos en anteriores trabajos (Costa y Fernández, 1992: 310-314; Benito et alii, en prensa: nota 4), hay suficientes argumentos para plantear la existencia de grupos humanos indígenas en el momento del establecimiento fenicio en la isla, aunque éstos probablemente fueran absorbidos o eliminados con relativa rapidez. En este sentido, las principales evidencias son los enterramientos de can Sergent I (Topp, Fernández y Plantalamor, 1979), con dataciones calibradas de $\mathrm{C}-14$ de 800 y 700 a.C., las cuales han sido cuestionadas y presentadas como resultado de una presunta contaminación de las muestras, sin otro argumento de peso que ser mucho más modernas de lo que se esperaba (Gómez y San Nicolás, 1988: 212; Gómez, 1995: 446). 
Además, tenemos un grupo de elementos de bronce, que se han ido incrementando con nuevos hallazgos -en parte aún inéditos-, y que responden a tipos propios del Bronce Final, los cuales pueden datarse dentro del primer milenio, sobre todo en los siglos vill-vII a.C. Dichos elementos, en su mayoría aparecidos en depósitos u ocultamientos cuya deposición difícilmente podría ser atribuida a los fenicios - a pesar de algunas afirmaciones en sentido contrario- permiten vincular lbiza y Formentera a las amplias redes por las que circulaban dichos productos, desde el Atlántico hasta el Mediterráneo central y oriental, en los momentos previos y contemporáneos a la presencia fenicia en Occidente (Costa y Fernández, 1992: 324-326). Por otra parte, la existencia en el depósito de can Marià Gallet de láminas metálicas con apéndices laterales y cono de fundición atribuibles a una producción del Sudeste, tal vez dirigida a los fenicios y que incluso ha sido interpretado como un sistema pre-monetal (González Prats, 1985), permite plantear que los fenicios se sumaron a estas redes indígenas por las que circulaban estos productos metálicos $\mathrm{y}$, superponiéndose a ellas, las integraron en las suyas propias, como ya hicieran en otros lugares (Aubet, 1993; Eadem, 1995).

Hoy por hoy, las evidencias arqueológicas del asentamiento fenicio en Ibiza (figura 1) se concentran en dos puntos: sa Caleta y la bahía de Eivissa. Hay, además, diversos hallazgos en superficie de fragmentos cerámicos, por lo general anfóricos, en diversos puntos de las Pitiüsas, como en la punta de Joan Tur Esquerrer, la illa Grossa, la talaia de Jesús, el puig de ses Torretes y la punta des Jondal en la isla de lbiza, y en el islote de s'Espalmador y en sa Cala en la de Formentera (Ramón, 1985 a: 19), que podrían ser reflejo de frecuentaciones o establecimientos efímeros en diversos lugares de las Pitiusas, o bien, dada la estratégica posición de todos ellos, del establecimiento de puntos de control del entorno marítimo-terrestre (Costa y Fernández, 1990 a: XIII; ídem, 1993 a). Por razones que hoy no estamos en condiciones de explicar satisfactoriamente, Formentera no fue objeto de ocupación permanente y, según parece, quedará varios siglos deshabitada (González y Díes, 1993).

Sa Caleta es una pequeña ensenada al Suroeste de la isla, en el término municipal de Sant Josep de sa Talaia, donde desemboca un torrente del mismo nombre, junto al que se encuentra una pequeña península, de superficie prácticamente plana y delimitada por acantilados de poca altura, en buena parte destruida por la acción del mar, y que es conocida como sa mola de sa Caleta. Desde este punto es visible la ciudad de Eivissa, de la que dista $9,5 \mathrm{~km}$. en línea recta. En este lugar, descubierto como yacimiento en 1978 (Ramón, 1981 a: 29-30), y en curso de excavación desde 
1986, se encuentra un extenso asentamiento, paralelizable con muchas de las factorías fenicias de Andalucía oriental, con unos $30.000 \mathrm{~m}^{2}$ de extensión, calculándose que originalmente tendría unas $4 \mathrm{Ha}$. Hasta ahora únicamente se ha dado a conocer un avance preliminar (Ramón, 1991 b), así como breves notas al respecto (Ramón, 1992: 456-460), a partir de los cuales podemos decir que está formado por un gran número de construcciones de planta generalmente rectangular, a veces ligeramente trapezoidales, que muestran la existencia de dos fases constructivas, ya que de plantas simples pasan a ser compartimentadas en diversas estancias en un segundo momento. No existe una orientación fija en todo el conjunto, sino que las diversas casas están separadas por estrechos callejones que desembocan en plazoletas de forma irregular. Hay que señalar la existencia de algunos hornos domésticos y otros de probable carácter industrial para fundir metales.

Los materiales son numerosos y diversos, destacando los cuencos de pasta gris, las lucernas, platos y cuencos carenados de barniz rojo, las jarras

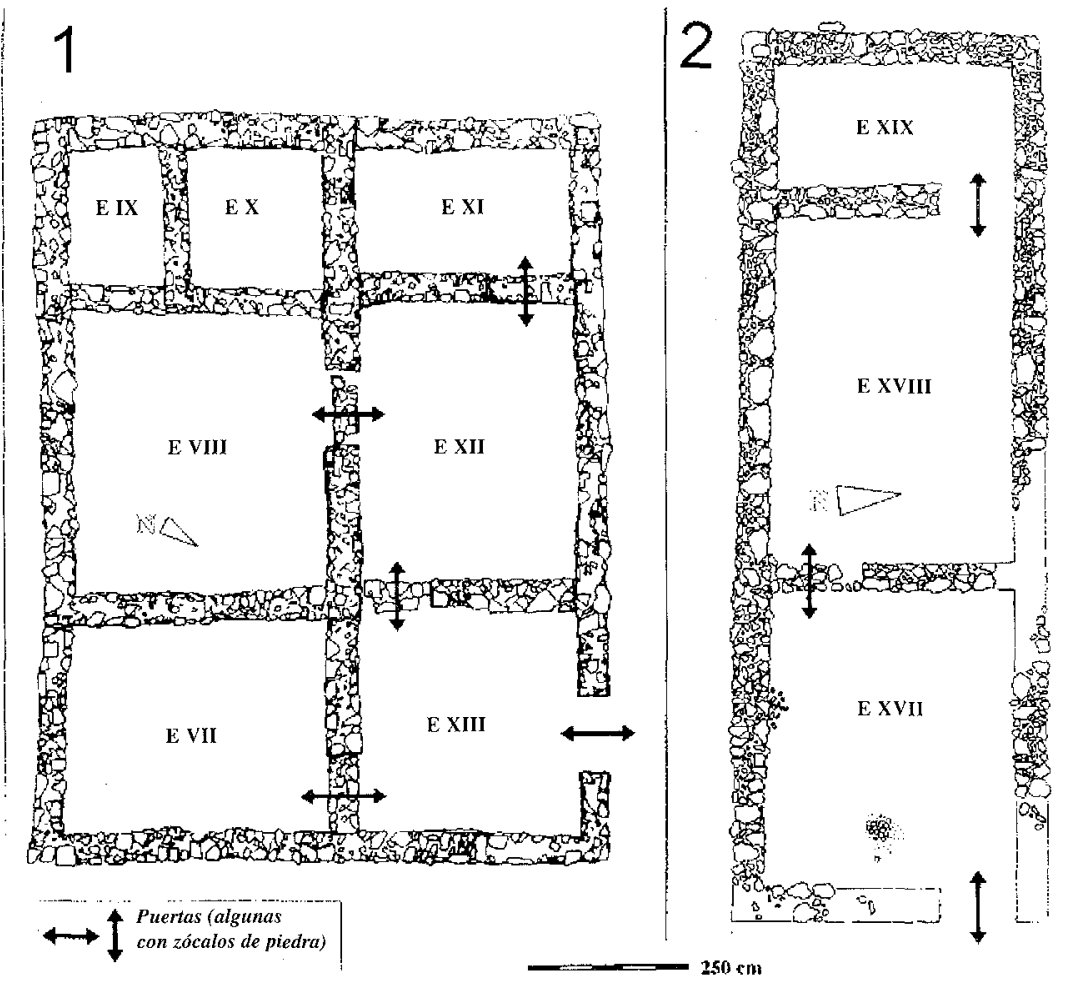

Figura 2. Sa Caleta, «barrio Sur»: Planta de dos unidades arquitectónicas (según Ramón, 1996). 
pythoides y las globulares con asas de sección geminada y decoración polícroma, los cuencos trípodes, ollas y cuencos hechos a mano, en su mayoría de origen fenicio-occidental, así como ánforas fenicias occidentales y otras de perfil ovoide del Mediterráneo Central (figura 3). Cabe también señalar el hallazgo, por todo el yacimiento, de nódulos de galena argentífera, tanto en estado natural como semifundida, pequeños cuchillos de hierro y bronce, anzuelos de bronce, molinos de arenisca, toberas de horno, así como algunos fragmentos de huevo de avestruz, ámbar y fusayolas (Ramón, 1981 a: 29-30, figuras 10-13; ídem, 1991 b: 180-182, figuras 3-6, lám. II).

Lógicamente, no entraremos a analizar este importantísimo yacimiento que, sin duda, nos proporcionará una información esencial sobre la dinámica del primer establecimiento fenicio conocido en lbiza, pero sí señalaremos que los materiales - a excepción de los fragmentos anfóricos más antiguos anteriormente mencionados- muestran una existencia corta, como ya hemos indicado en dos fases, que se extiende tan sólo entre el último tercio del siglo vil a.C. y el primer cuarto del siglo vi a. C. (Ramón, 1991 b: 183).

En cuanto al asentamiento de la bahía de Eivissa, aunque la topografía señalaba el puig de Vila como probable núcleo inicial, hasta los sondeos en el Castillo y en la Almudaina que han ofrecido algunos indicios (Ramón, 1991 a: 21; idem, 1994: 352-353) que todavía no se han dado a conocer en detalle, y del descubrimiento aún inédito de un posible sector de enterramientos arcaicos en la Calle de Santa María (Gurrea y Ramón, en prensa), solamente se conocían algunos hallazgos dispersos, entre los que destaca un fragmento de ánfora ática SOS (Ramón, 1983: 111-113; Costa y Gómez, 1987: 43), que pudieran señalar de manera directa la existencia de un establecimiento arcaico en la cima de este cerro que domina la bahía. Lamentablemente, el desarrollo de la ciudad sobre el mismo emplazamiento ha motivado que las fases posteriores, desde la época púnica hasta nuestros días, hayan borrado casi todos los vestigios del poblamiento inicial, ya que nada más que algún fragmento residual se ha documentado en los estratos inferiores de los sondeos realizados. Así, al margen de la enigmática punta de Joan Tur Esquerrer, en el extremo meridional del puig de Vila y a pocos centenares de metros del recinto amurallado, donde se encontró en superficie un abundante conjunto de fragmentos cerámicos de no fácil interpretación (Ramón, 1981 a: 28-29; ídem, 1992: 468-470; ídem, 1994: 353356), la prueba más fehaciente de la existencia de ocupación fenicia en la bahía ibicenca lo constituyen el conjunto de enterramientos de incineración que en los años setenta y ochenta se documentaron en el puig des Molins (Ramón, 1981 a; Fernández, Gómez y Gurrea, 1984; Costa, 1986, 1988 y 1991; Costa, Fernández y Gómez, 1991; Gómez et alii, 1990). 

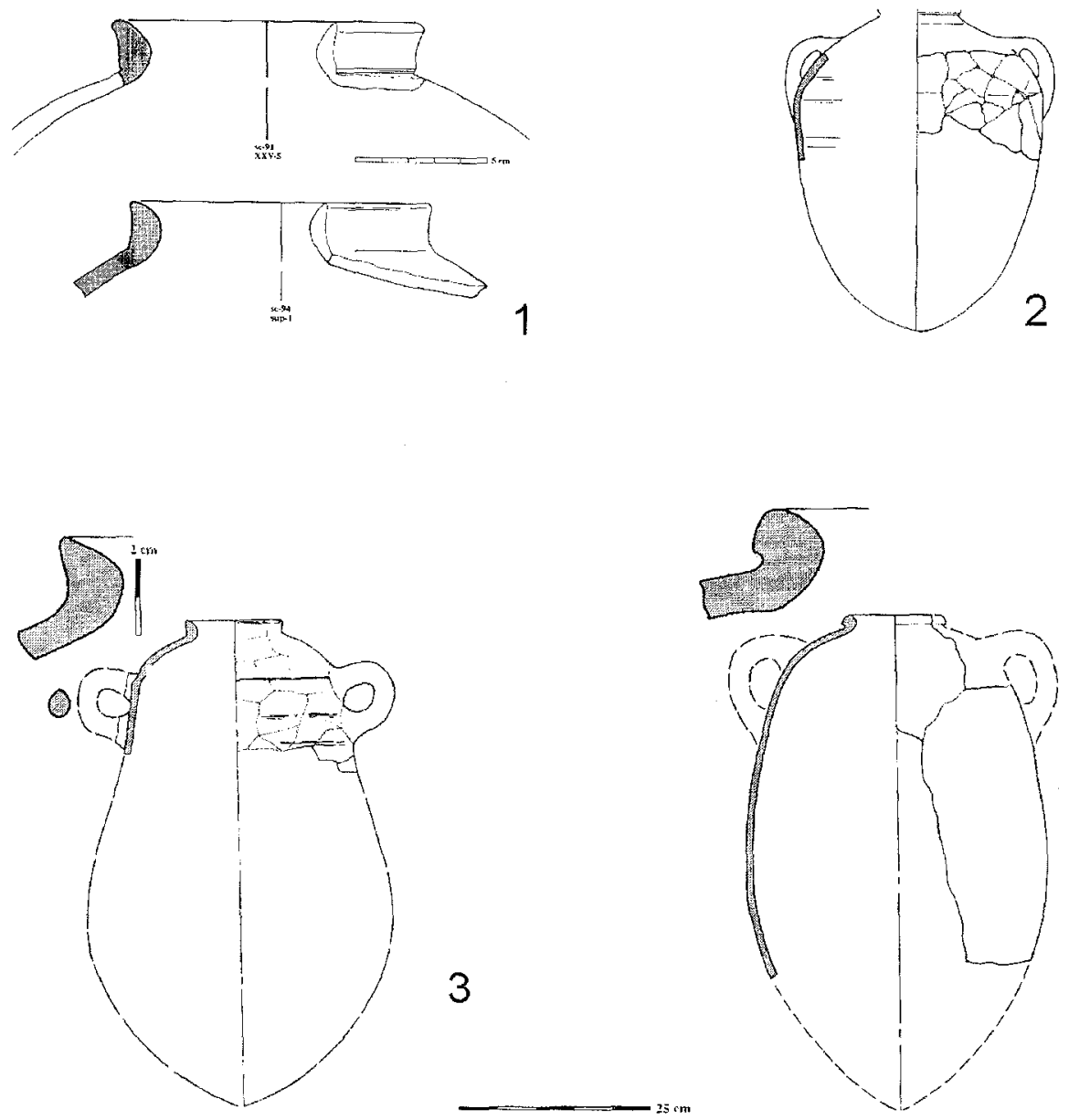

Figura 3. Sa Caleta, hallazgos anfóricos: (1) T-10.1.1.1 fenicio-occidental; (2) T-3.1.1.1 centro-mediterránea; (3) T-10.1.2.1 fenicio-occidental y (4) T-2.1.1.2 centro-mediterránea (según Ramón, 1996). 
No insistiremos sobre la tipología de estas sepulturas, ni sobre las características de estos enterramientos, ni sobre los rituales funerarios, que ya han sido extensamente publicados en la bibliografía reciente. Señalemos tan sólo que todos los enterramientos son de incineración, que no se ha hallado ningún ustrinum sino que parece que las cremaciones se realizaban independientemente en un lugar no establecido, cerca o dentro de la tumba, y que en conjunto pueden distinguirse dos grupos de sepulturas, cada una de ellas con diversas variantes: el primer grupo son las deposiciones realizadas directamente sobre la roca aprovechando grietas o concavidades naturales que, en ocasiones, han sido retocadas, o bien en orificios circulares tallados artificialmente, con los restos óseos incinerados depositados en interior de jarras próximas al tipo Cruz del Negro (Aubet, 1976-78: 267-287) $\circ$ al tipo R-5 o R-4 de Vuillemot (1965, figura 17), (figura 4), o directamente en la sepultura rodeados y/o cubiertos con piedras de pequeño o mediano tamaño. El segundo lo constituyen las fosas, que pueden ser enterramientos primarios o, como es más frecuente, secundarios. Éstas pueden estar talladas en la roca o en la tierra y muestran una gran diversidad de tipos y variantes a tenor de sus características, tamaño, orientación y morfología, a la vez que su ritual funerario que resulta ser mucho más complejo que el grupo anterior. En líneas generales podemos diferenciarlas en: fosas simples, fosas con un pequeño canal en su fondo, fosas con resaltes laterales y fosas de forma irregular (Costa, 1991; Costa, Fernández y Gómez, 1991).

En cuanto a los ajuares se observa que en los enterramientos efectuados en los huecos en la roca, cuando existen, se reducen a alguna pieza de cerámica - generalmente una ampolla Bisi 3 (figura 5) - y a algún elemento de joyería o adorno personal del difunto. Por el contrario, el ajuar que hallamos en las fosas suele ser más numeroso, estando compuesto por platos y lucernas fenicias de barniz rojo, ampollas globulares del tipo Bisi 3, ollas realizadas a mano y, en alguna ocasión un kantharos etrusco de bucchero nero (figura 6, no 2) y un aryballos corintio (figura $6 n^{\circ} 3$ a y b). Igualmente aparece alguna cerámica de producción local -cuencos, platos, urnas. Es de destacar la presencia en algunas de estas tumbas arcaicas de algunos elementos de joyería, como colgantes en forma de nicho en plata y en oro, escarabeos egipcios de pasta, en alguna ocasión montado en un anillo de plata con montura basculante, así como cuentas de collar de vidrio monócromas o esferoidales y cilíndricas talladas en piedras duras. Estos elementos, fueron colocados en el enterramiento tras la cremación del cadaver, pues nunca estan afectados por el fuego (Costa, Fernández y Gómez, 1991: 791) y, a pesar de su sencillez, parecen denotar un cierto grado de distinción social. 

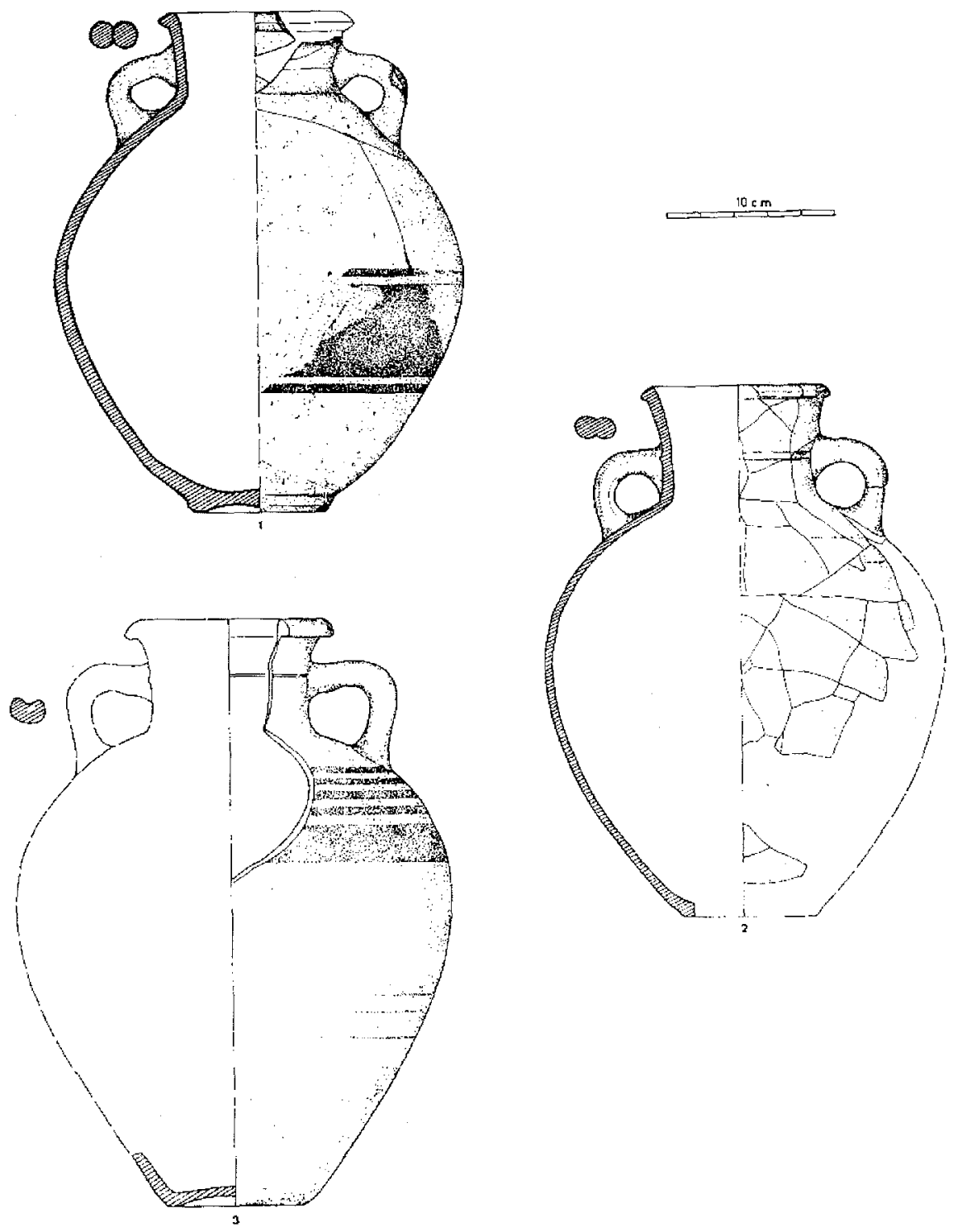

Figura 4. Necrópolis del puig des Molins: urnas cinerarias. 

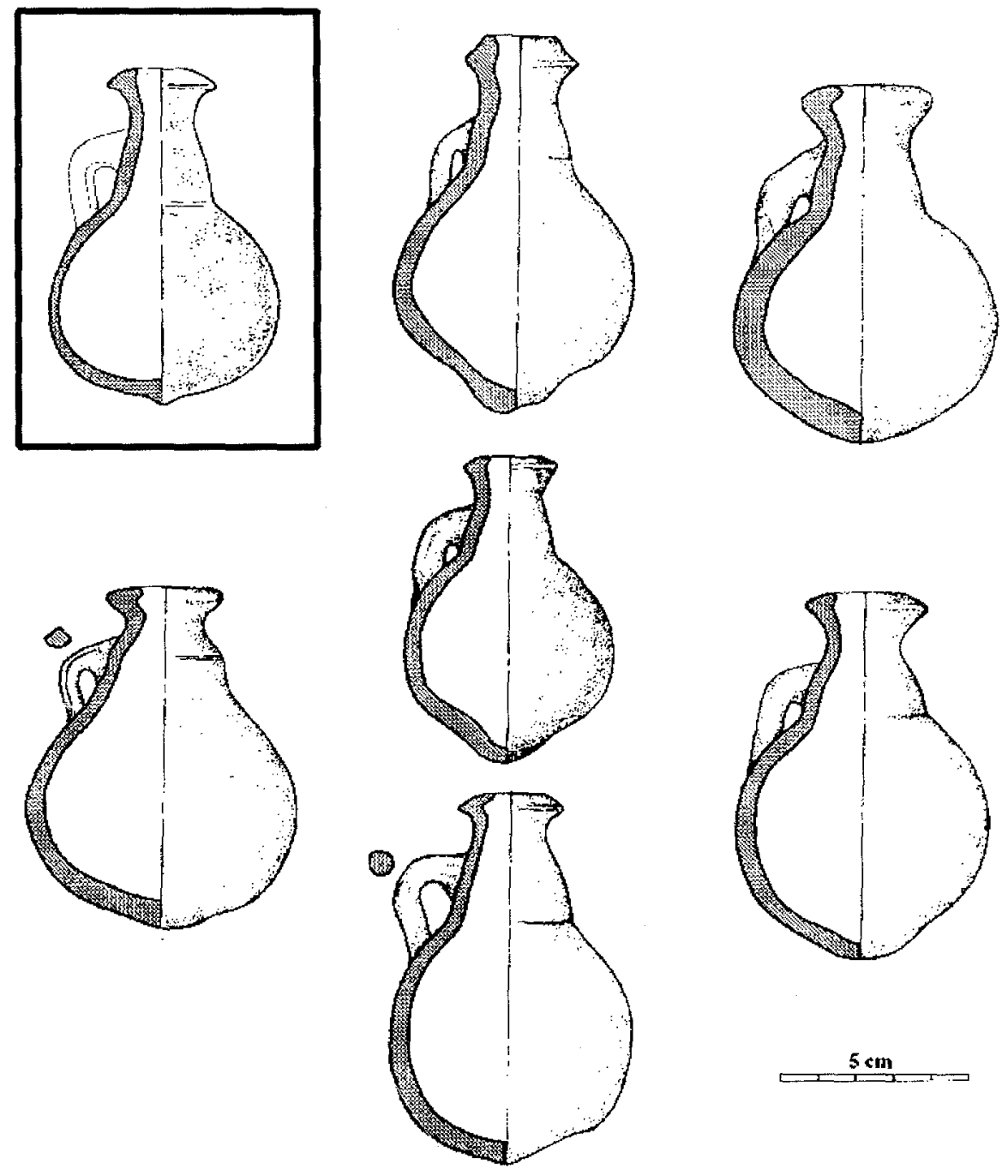

Figura 5. Ampollas fenicias del tipo Bisi 3 de las necrópolis de mas de Mussols (en el recuadro) y del puig des Molins (según Ramón, 1996). 

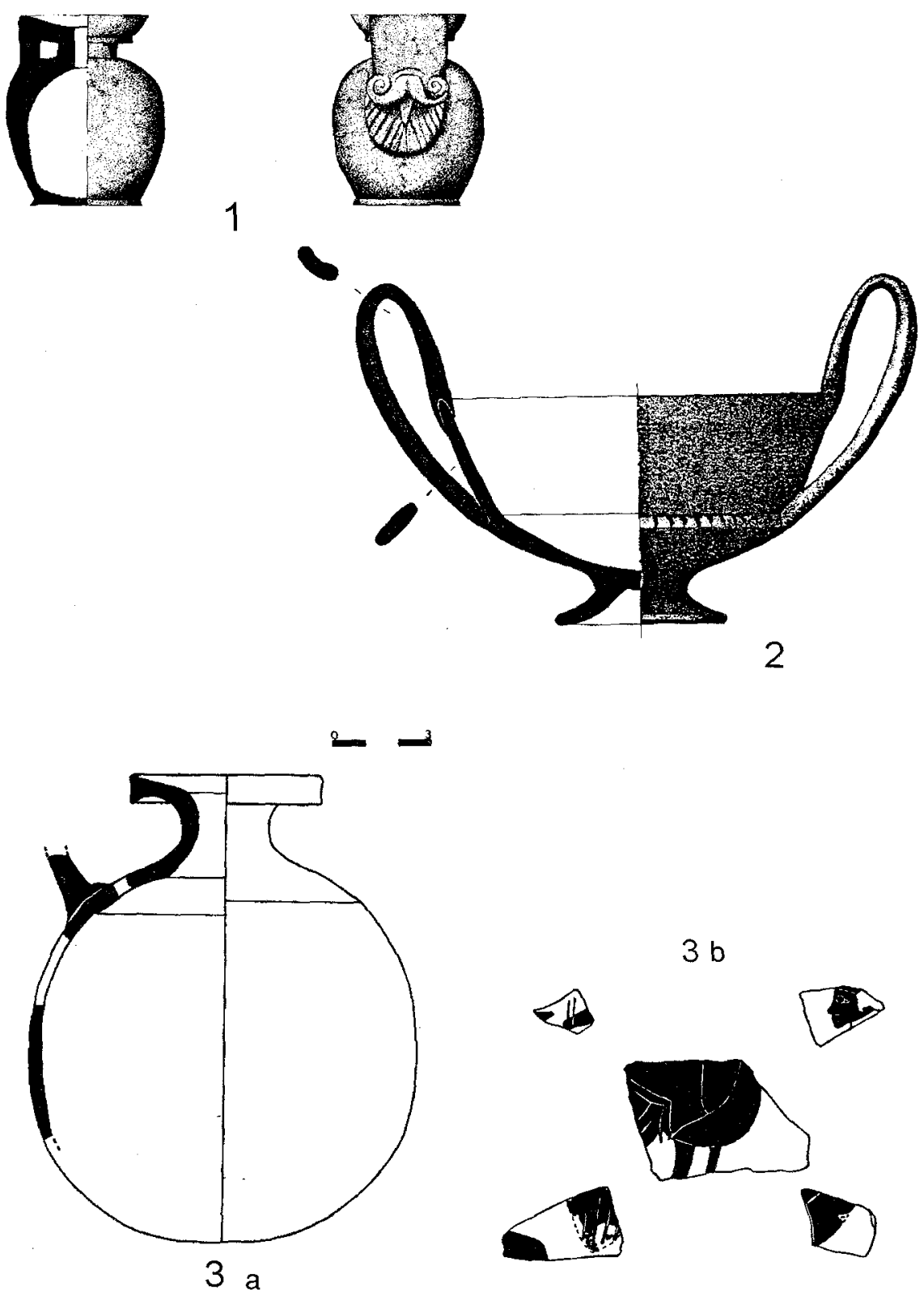

Figura 6. Necrópolis del puig des Molins, materiales arcaicos de importación: (1) aryballos de fayenza de Naucratis; (2) kantharos de bucchero nero; (3) aryballos corintio, reconstrucción (a) y fragmentos con decoración (b). 
La cronología de este conjunto se sitúa principalmente entre los últimos años del siglo vil a.C. o ya en los primeros del siglo vI a.C., y la segunda mitad del siglo vi a.C., si bien, como veremos más adelante, algunos de estos enterramientos de incineración se han de datar incluso en un momento posterior. Es también importante destacar que gracias al estudio antropológico de las incineraciones (Gómez et alii, 1990: 186-200), sabemos que el componente fenicio de población estaba constituido por individuos jóvenes, como resulta lógico en una empresa colonial que comportaba duras condiciones de vida, tal y como lo refleja la elevada tasa de mortalidad infantil, así como la femenina a causa de partos o embarazos difíciles.

Hace algunos años en un trabajo calculamos la extensión de este primer cementerio en unos 2.500-3.000 $\mathrm{m}^{2}$ (Costa y Fernández, 1993 a: figura 3), cifra que parecía ajustada según las evidencias disponibles en aquel momento - principalmente los sondeos realizados en el sector Noroeste de la necrópolis (Ramón, 1981 a; Fernández, Gómez y Gurrea, 1984), así como el solar de can Partit (Costa, 1986, 1988 y 1991), de triste recuerdo por su salvaje destrucción (Costa y Fernández, 1990 b; Costa, Fernández y de Hoyos, 1996)-. No obstante, la intervención de urgencia en el solar no 47 de la Vía Romana, en el jardín de la Clínica Ntra. Sra. del Rosario llevada a cabo por el Servicio de Arqueología del Consell Insular de Ibiza y Formentera, ha permitido ampliar la extensión del área de enterramientos arcaicos, hasta una cifra de - a nuestro juicio- aproximadamente $6.000 \mathrm{~m}^{2}$ (Costa y Fernández, 1992: 330), aunque el excavador la cifra en 8.000/10.000 m² (Ramón, 1992: 462; ídem, 1994: 337).

Otro importante hallazgo al que hemos de hacer referencia es el conjunto de cerámicas fenicias halladas, junto con materiales de épocas diversas, en el relleno de un pozo medieval relacionado con el asentamiento islámico existente al pie de la vertiente Nord-oriental del puig des Molins (Fernández, Gómez y Gurrea, 1984: 791; Gómez et alii, 1990: 47-71; Costa, Fernández y Gómez, 1991: 777). La cantidad y diversidad de piezas de este conjunto, entre las que encontramos material anfórico, cerámica doméstica, cuencos de pasta gris, vajilla de barniz rojo, cuencos trípode, jarras con decoración pintada, algún fragmento de cerámica hecha a mano y un fragmento de un vaso de alabastro, no permite considerarlos como de procedencia funeraria, ya que la asociación de estos distintos tipos de vasos parece más propia de contextos de hábitat. Por ello se ha planteado la hipótesis de que podrian corresponder a una zona de hábitat y/o instalaciones portuarias situadas entre el puig de Vila y el puig des Molins y, por lo tanto, próximo a la antigua línea de costa. Pero un hecho que cabe señalar es que su procedencia en el relleno de un elemento muy posterior en el tiempo, juntamente con materiales muy diversos, no permi- 
te que pueda ser interpretado como un «conjunto arqueológico cerrado», como parece que algún autor lo viene considerando. Este punto creemos que es importante remarcarlo por sus implicaciones cronológicas, ya que, a diferencia de otras opiniones, creemos que el lapso temporal representado por este grupo de piezas podría ser relativamente largo, probablemente desde los últimas décadas del siglo vII, o primeros años del VI a.C., hasta mediados de este siglo (Costa y Fernández, 1992: 330).

Pero, si hasta hace unos años no se habían planteado dudas sobre la contemporaneidad de los dos enclaves ibicencos - sa Caleta y la bahía de Eivissa-, en los últimos años J. Ramón ha propuesto una nueva hipótesis por la que el asentamiento de la bahía de Eivissa se habría establecido cuando se abandona sa Caleta, y serían los habitantes de este enclave los que se instalarían en el puig de Vila como consecuencia de un crecimiento de la actividad y desarrollo del poblamiento que requeririan de unas nuevas condiciones que la pequeña península ya no podía ofrecer (Ramón, 1992; ídem, 1994). Así pues, la ocupación fenicia de la bahía de Ibiza se tendría que situar, según este autor, a partir del 600/570 a.C. y tendría ya un carácter de ciudad organizada, no sólo en relación a su magnífico puerto, sino sobre todo al control y explotación del fértil territorio circundante. Esta hipótesis resulta altamente sugestiva, por cuanto reproduce en lbiza una dinámica de poblamiento análoga a la documentada en la bahía de Málaga, donde la actual capital provincial, según recientes investigaciones, fue fundada a principios del siglo vi a.C. (Gran-Aymerich, 1991), tras el abandono de diversos enclaves costeros de menor entidad, como el Cerro del Villar (Aubet, 1992). Ello resulta doblemente atractivo, por cuanto dicha propuesta reforzaría los vínculos de Ibiza con el área andaluza, permitiendo situar nuestra isla en los mismos procesos evolutivos que afectaron a la región de origen de sus primeros colonos. Su principal argumento, sin embargo, no se basa en diferencias de carácter tipológico entre los materiales de ambos lugares que permitieran establecer una diacronía entre ambos, sino en la homogeneidad de las pastas de las cerámicas fenicias del área de la bahía de Eivissa - tanto en el puig de Vila y la punta Joan Tur Esquerrer como en la necrópolis del puig des Molins--, que en su mayoría serían de fabricación local. Y esta incipiente manufactura insular no sólo produciría ánforas - definidas como tipo PE 10-, sino también buena parte de la vajilla común y de barniz rojo. Por tanto, los materiales de la ciudad representarian una fácies consecutiva, y más reciente que la de sa Caleta, cuyos materiales son exclusivamente de importación (Ramón, 1991 a: 22-23; ídem, 1991 b: 185-187; ídem, 1992: 472-474; ídem, 1994: 364-365; ídem, 1996: 412-414).

Por nuestra parte, nos parece que, hoy por hoy, resulta realmente difícil, 
con los elementos existentes, determinar si puede haber una diferencia cronológica, que en todo caso creemos que sería mínima, entre el establecimiento de los dos enclaves. Por ello preferimos esperar, por una parte, a la publicación detallada de los materiales de sa Caleta y, por otra, a tener unos resultados de análisis de pastas cerámicas, que confirmen o desmientan el carácter local de la producción del área de la ciudad, para pronunciarnos definitivamente. De cualquier manera, creemos que el diferente carácter de los dos enclaves - factoría industrial y colonia de poblamientono implican necesariamente una separación cronológica, sino una funcionalidad diversa (Costa y Fernández, 1992: 332), aspecto éste que su excavador admite, aceptando que los enclaves de la bahía de lbiza y el de sa Caleta no tienen el mismo planteamiento socio-económico (Ramón, 1991 b: 187). Así pues, como ya hemos indicado en un reciente artículo (Costa y Fernández, en prensa), no nos parece ilógico que sa Caleta fuera un enclave complementario e incluso dependiente del de la bahía de Eivissa.

Hay varios aspectos que sugieren esta posibilidad. En primer lugar es la elección del emplazamiento de sa Caleta, cuando no hay duda de que el lugar resulta muy poco apropiado al ser un lugar batido por el oleaje y los fuertes vientos del S. y S.O. Prueba de ello es la fuerte erosión que este lugar ha sufrido y que ha provocado un notable retroceso de la costa en esta zona y con ello la desaparición de una parte del yacimiento (Schulz, 1997: 23-25, figura 5). Igualmente, si la elección estaba condicionada al hecho de disponer de una escala en las rutas fenicias de navegaciōn entre la Península Ibérica y Cerdeña, como disponer de una base permanente desde la que alcanzar nuevas áreas de captación de productos y materias primas en Cataluña y la Narbonense, lo lógico hubiera sido que la elección hubiera recaído en la bahía de Eivissa en la costa oriental, y la de Sant Antoni de Portmany en la occidental, lugares mucho más aptos para el tráfico marítimo.

Cabe pues preguntarse si los fenicios fundarían un establecimiento permanente en un lugar poco idóneo como sa Caleta, desechando otros a todas luces mucho más aptos, como la bahía de Eivissa, a no ser que causas de fuerza mayor les obligasen a ello, cosa que el estado actual de nuestros conocimientos no permite plantear.

De lo que no hay duda, en cualquier caso, es que abandonada sa Caleta, a partir del segundo cuarto del siglo vi a.C., el asentamiento de la bahía de Eivissa se convierte en el único enclave, o al menos el principal, en donde se concentrará todo el poblamiento y la actividad económica, tanto en lo que se refiere al comercio exterior, como a la explotación de los recursos propios de la isla, como parecería indicarlo el inicio de la produc- 
ción de envases industriales tipo PE-10 (Ramón, 1991 a: 100-102), aunque en estos momentos seguramente se explotarían sólo los fértiles llanos del entorno de la ciudad, además de los recursos marítimos. También -si se confirma definitivamente su producción local de la mayor parte de las cerámicas fenicias de la zona de la bahía de Eivissa- sería ahora cuando se pondrían en funcionamiento las primeras industrias alfareras, hecho que respondería perfectamente a una situación de desarrollo de la colonia, que tiende a su autoabastecimiento (Costa, 1994: 85; Costa y Fernández, en prensa). Por otro lado, en estos momentos el panorama material presenta también cambios significativos, ya que además de constatarse la desaparición de los materiales de origen fenicio occidental, aparecen algunas cerámicas de importación de origen griego y etrusco, tales como kantharos de bucchero nero, aryballoi etrusco-corintios y corintios, objetos de faienza de Naucratis, ánforas SOS, además de algún pequeño cuenco y un buen número de ampollas fenicias del tipo 3 de Bisi, procedentes del Mediterráneo Central (Almagro, 1978; Ramón, 1982 b; ídem, 1983; Costa y Gómez, 1987; Gómez et alii, 1990; Gómez, 1991 b; Costa, 1994).

Todos estos hechos han llevado a plantear la hipótesis de que lbiza, además de inciar su propio desarrollo, cambiaría su marco de influencias y de relaciones, en un período en que se suceden profundos cambios, tanto en Oriente - con la caída de Tiro en el 573 a.C.,- como en Occidente donde ahora tendría lugar la supuesta «crisis» de inicios del siglo vi a.C. (Aubet, 1987: 276-278), que darán lugar a importantes transformaciones y al abandono de diversos yacimientos andaluces - que suponen en algunos casos una nueva redistribución del poblamiento sobre el territorioademás de la interrupción de la explotación argentífera de Riotinto. Otro factor que contribuye a complicar el panorama es la presencia griega en Occidente, que parece intentar introducirse en el mercado tartésico, según la interpretación que se ha dado a las numerosas cerámicas arcaicas halladas en Huelva (Fernández Jurado, 1984; Cabrera, 1985, 1986 y 198889) y que finalmente se establecerán en la esquina nord-oriental mediterránea, donde fundan Marsella y Ampurias, de donde desaparece la presencia fenicia. En cualquier caso, aunque se ha cuestionado y matizado diversos aspectos de esta "crisis" (Alvar, 1991), parece que, en estos momentos de cambios y reorganizaciones del mundo fenicio de Occidente, Ibiza entraría también en relación con los enclaves fenicios del Mediterráneo Central, convirtiéndose en un centro de redistribución de los productos de esta procedencia hacia el Occidente peninsular (Costa y Gómez, 1987; Gómez, 1991a; Gómez, 1992; Gómez et alii, 1990). De esta manera, la colonia ebusitana quedaría integrada en un nuevo y más complejo marco de relaciones cosa que, probablemente, debió de resultarle 
beneficiosa. $Y$, aunque este planteamiento ha sido cuestionado (Ramón, 1996: 413-414), otros pensamos que esta etapa en la que Ibiza se integra en las redes del comercio fenicio internacional - cuyo epicentro se desplaza cada vez más desde el Estrecho hacia el Mediterráneo central, pues las relaciones internacionales vuelven a reorientarse hacia el mundo tirrénico y griego oriental (Aubet, 1995: 232) - , constituyó el precedente de la entrada de Ibiza en la esfera de influencia de Cartago (Costa, 1994).

\section{LA COLONIZACIÓN PÚNICA DE IBIZA (CIRCA 525-450 A.C.)}

A partir del último tercio del siglo vi a.C., la arqueología refleja una serie de cambios que se han podido documentar principalmente en la necrópolis del puig des Molins.

En primer lugar la introducción del ritual de la inhumación. Este hecho comporta, igualmente, la aparición de nuevos tipos de sepultura: los hipogeos de pozo rectangular y cámara cuadrangular excavados en la roca. En consecuencia, también cambia la cantidad y composición de los ajuares funerarios, que ahora incrementan notablemente el número de objetos presentes en las sepulturas, así como su calidad y variedad, puesto que a partir de ahora encontramos por vez primera huevos de avestruz, figuritas de terracota, amuletos egipcios de pasta, además de un variado repertorio de elementos cerámicos. Los escarabeos egipcios continúan apareciendo, así como los elementos de joyería en plata y oro, y ornamentos personales, principalmente cuentas de collar de pasta vítrea, monocromas y con decoración oculada.

Los hipogeos más antiguos documentados fueron los del solar $\mathrm{n}^{0}$ 10-12 de la calle León (Fernández et alii, 1984; Gómez et alii, 1990: 78-88; Costa, Fernández y Gómez, 1991: 780). Éstos se caracterizan por sus grandes dimensiones, así como por su cuidada construcción, que queda patente en una notable verticalidad de las paredes de cámaras y pozos, que presentan pequeñas oquedades laterales, a modo de peldaños para facilitar el acceso. La puerta de entrada a la cámara no ocupa toda la anchura del pozo y se encuentra cerrada por grandes losas de piedra local sin desbastar (figuras 7 y 8 ). En definitiva, estas características diferencian claramente estas sepulturas, que hemos de datar en el último tercio del siglo vı a.C., de los hipogeos conocidos tanto en el puig des Molins como en el resto de la isla. Pero además, hay que remarcar que las sepulturas de la calle León aparecen como un grupo aislado, dado que a su alrededor no había ninguna otra sepultura ni contemporánea, ni anterior, ni posterior, como si se tratara de un conjunto perfectamente individualizado y diferenciado del resto. 

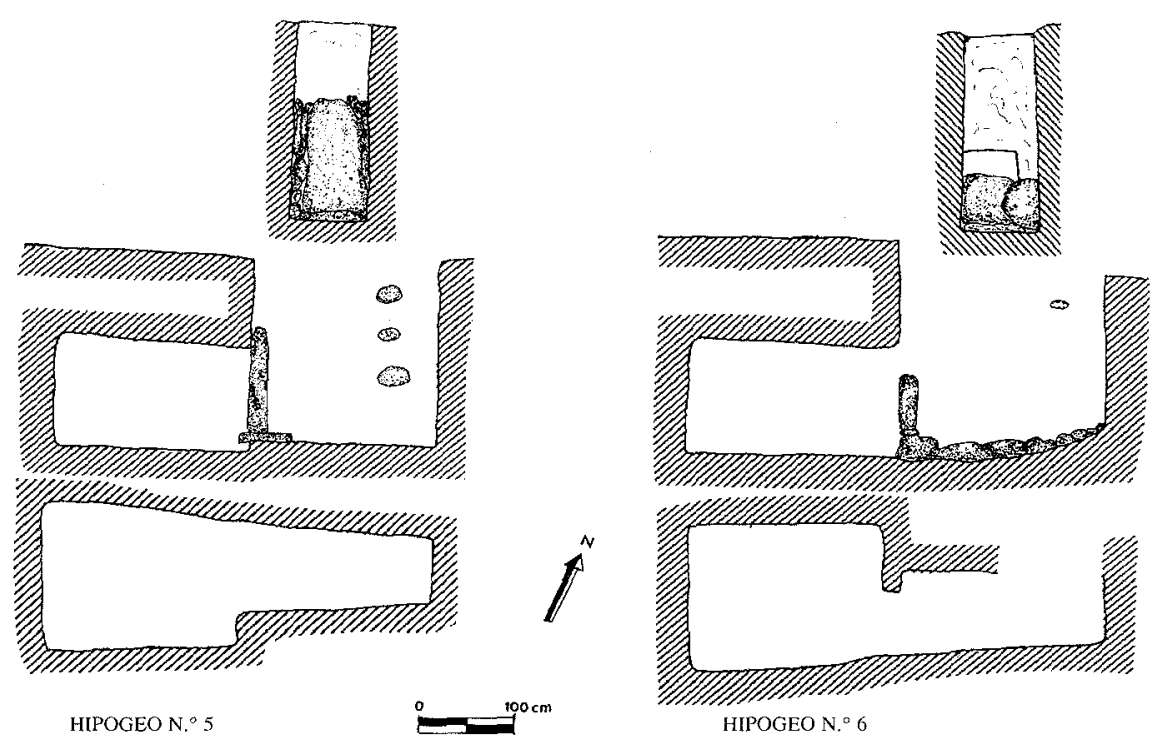

Figura 7. Necrópolis del puig des Molins: Hipogeos núms. 5 y 6 de las excavaciones del solar núm. 10-12 de la C/León (Eivissa).

Otro hecho significativo de finales del siglo vi a.C. es la entrada en funcionamiento del santuario de la llla Plana, aunque no se descarta que el lugar fuera considerado como sagrado en un momento anterior, tal vez a principios de este mismo siglo como apuntan con distintos argumentos diversos autores (Hachuel y Marí, 1988: 57, 60 y 71-72; Ramón, 1991 a: 23 nota 10; ídem, 1992: 472; ídem, 1994: 357, lám. VII, 6). Igualmente algunos materiales del Puig den Valls, posiblemente también de carácter cultual, podrían datar de finales de la sexta centuria o principios de la siguiente (Román y Calvet, 1906: XI, 3; XVIII, 10-12 y XXXI, 5-6; Almagro, 1980: 84, lám. XXIV, 4).

En cuanto a los materiales cerámicos (figura 12), las formas características de este momento -Eb. 5, Eb. 12, Eb. 16, Eb. 61, Eb. 65, etc. (Fernández, 1992; Fernández y Costa, 1995) - que corresponden al inicio de la producción local a nivel industrial, copian fielmente prototipos morfológicos propios del área del Mediterráneo central (Ramón, 1981 b: 162). No obstante, este cambio en las formas cerámicas no se produce en otras zonas fenicias del Occidente (lbídem: 169). Además, en el último cuarto del siglo vI se incrementa la producción y exportación de envases industriales, en particular el tipo PE-12, y aparece el PE-21, que imita el perfil de una ánfora 

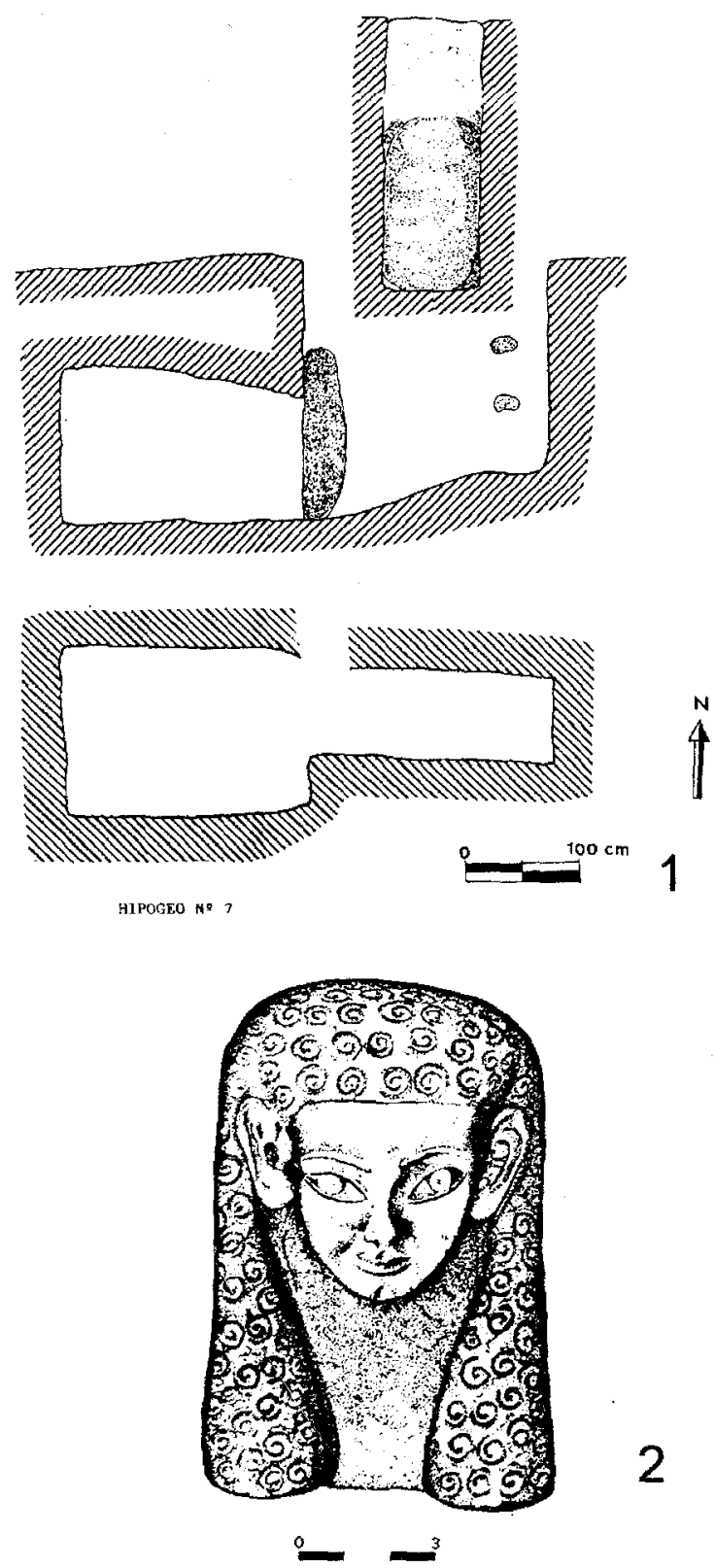

Figura 8. Necrópolis del puig des Molins: (1) Hipogeo núm. 7 de las excavaciones del solar núm. 10-12 de la C/León (Eivissa) y (2) prótomo femenino de terracota, aparecido junto a un enterramiento infantil realizado en el pozo de este hipogeo. 
griega arcaica (Ramón, 1981 c: 109-110; ídem, 1991 a: 115-116), iniciando así una larga tradición púnico-ebusitana de copiar perfiles de vasos foráneos aunque se trate de recipientes producidos en mucha menor cantidad con respecto a los de la clase 1.

En conjunto, todos estos hechos reflejan una situación bien diferente de la fase anterior, pues parece que ahora se producen cambios bien significativos en la isla, que hemos de relacionar con su entrada en el marco de influencia de Cartago. En efecto si, tal como hemos visto, a lo largo de la primera mitad del siglo vI a.C. parece que lbiza se integra en un importante circuito comercial que parte del Mediterráneo Central, cuando éste queda bajo control cartaginés, a partir de la intervención de la capital norte-africana en los asuntos mediterráneos, nuestra isla no podía quedar al margen de sus intereses.

J. Ramón defiende que en este desarrollo las aportaciones púnicas foráneas, aunque pudieron existir, no tuvieron un peso preponderante, y que el crecimiento de la isla responde a un contexto de desarrollo generalizado del Mediterráneo centro-occidental (Ramón, 1995 b: 32). Por nuestra parte, creemos que, en estos momentos, la isla no sólo entraría en la esfera política, económica y cultural del ámbito púnico centro-mediterráneo, sino que, también, la investigación arqueológica aporta evidencias relacionables con la llegada de nueva población. Parece lógico ver los hipogeos arcaicos de la calle León como un conjunto de sepulturas correspondientes a un grupo humano diferenciado que se entierra en un lugar concreto e individualizado de la necrópolis, próximo pero periférico al primitivo cementerio fenicio. Por otra parte, la introducción de la inhumación y la aparición de grandes sepulturas, con una notable inversión de energía en su construcción (que en el caso del único que conservaba su contenido intacto - Hipogeo 5-, se amortiza con una sola deposición funeraria), así como el incremento en la cantidad y calidad que desde ahora experimentarán los ajuares funerarios, entendemos que no sólo constituyen un hecho cultural y un cambio de tradiciones, sino que también son el reflejo de una nueva situación social y también económica de la colonia (Costa y Fernández, 1995 a). Además, el notable incremento tanto en extensión como en la apertura de nuevas sepulturas que experimenta el cementerio durante el siglo $v$ a.C., no parece que pueda ser explicada más que por la llegada, probablemente de manera escalonada, de nuevos contingentes de población que se unirian a la primitiva colonia fenicia (Costa y Fernández, 1988: 81; ídem, 1990 a: XVII; ídem, 1993 a; Costa, 1994).

En este sentido, como se ha argumentado con anterioridad (Costa y Fernández, 1992: 334; Costa, 1994: 91), Ibiza no es un caso aislado, el 
mismo Diodoro (XIV , 47, 4), siguiendo a Timeo, también describe Mozia como un ájtoikos de Cartago. Esta afirmación es evidente que se trata de un error sobradamente desmentido por la arqueología del enclave siciliano (Barceló, 1985: 279), pero como apunta Whittaker (1978: 75), podría estar relacionada con el establecimiento en el lugar de refuerzos de colonos procedentes de Cartago, cosa que justificaría la utilización del término ájo íkos así como el hecho de que Timeo, y con él Diodoro, atribuyese los hechos de mediados del siglo VII a.C., protagonizados por fenicios, a los cartagineses, que en realidad no tendrían una presencia efectiva, tanto en Mozia como en Ibiza, hasta un siglo más tarde.

Cabe señalar que existe igualmente la noticia del envío de colonos de Cartago, después de la destrucción de Himera, para fundar una nueva ciudad en Thermai en el 407 a.C. (Diod. XIII, 79, 8), así como indicios de colonización cartaginesa en otros lugares sicilianos como Selinus, Érix y tal vez alguno más. En cuanto a Cerdeña hay también algunas referencias a las fuentes antiguas de colonización cartaginesas, aunque muchas de ellas son incorrectas, como por ejemplo Pausanias $X, 17,9$, que confunde fenicios con cartagineses, atribuyendo a estos últimos la fundación de Caralis y Sulcis (Whittaker, 1978: 75). E, incluso, la presencia de libio-fenicios en el Sur peninsular, atestiguada por diversas fuentes, ha sido interpretada como producto de una colonización agrícola promovida por Cartago (López Castro, 1992 c). Recordemos también que, en estos momentos finales del siglo vi a.C., el territorio propio de Cartago era todavía reducido y no sobrepasaba el Cap Bon. Parece lógico, pues, que utilizara la colonización para aligerar la presión demográfica, como siempre habían hecho las ciudades fenicias; pero, además, esto le permitía establecer relaciones privilegiadas con centros comerciales de interés estratégico, como era Ibiza (Costa y Fernández, 1992: 335; Costa, 1994: 93).

Volviendo al poblamiento de nuestra isla, un hecho de trascendencia que cabe advertir es que, en contra de lo que venía afirmándose, incluso también por nosotros mismos (Costa y Fernández, 1988: 81; ídem, 1993 a:; Costa, Fernández y Gómez, 1991: 794), la aparición y generalización de la inhumación no comporta la radical desaparición de la cremación. En efecto, la revisión que estamos realizando de las fases de la necrópolis nos ha permitido comprobar como algunas sepulturas de incineración atribuidas al mediados del siglo vi a.C. (Gómez et alii, 1990: 159), que presentan elementos tales como platos, jarras, boles y lucernas de producción local sin barniz rojo, agujas, navajas de afeitar y campanitas de bronce, cuentas de collar de pasta vítrea y también, por primera vez, de oro, etc. se han de datar muy a finales de este siglo e incluso en las primeras 
décadas del siguiente, y son, por tanto, contemporáneos de los primeros enterramientos de inhumación. Así pues, la cremación de los cadáveres se mantendrá, aunque ya no sea el rito mayoritario, al menos hasta finales del primer cuarto del siglo v a C. (Costa y Fernández, 1992 y 1995 a; Costa, 1994). Además en los fondos del Museo Arqueológico de Ibiza y Formentera se conservan un cierto número de ollas globulares con tapadera de cierre hermético, del tipo que vulgarmente se denomina «urnas de orejetas»; varias, con decoración pintada de meandros verticales, bandas y líneas horizontales, proceden del puig des Molins. Una de ellas contiene una incineración infantil que se ha datado en el siglo III a.C. (Gómez, 1983), aunque nosotros no creemos que este tipo en concreto pueda datarse más allá, como mucho, del primer cuarto del siglo iv a.C., a diferencia de otras de la misma forma más evolucionadas, que sí pueden corresponder al siglo III a.C. (Fernández, 1992, vol. II: 37-38; Costa y Fernández, 1992: 335).

Esta cuestión merece una reflexión. ¿Qué significado puede tener la perduración durante más de medio siglo, aunque residual, de la cremación conviviendo con la inhumación? ¿Podemos pensar que este hecho refleja la existencia de una minoría de ascendencia fenicia que todavía conserva sus hábitos funerarios propios? No podemos dar una respuesta segura, pero esta hipótesis debe ser tenida en cuenta en la futura investigación.

En cualquier caso, el crecimiento demográfico, a la vez que obligaba a un incremento de la producción, permitía un cambio en el modelo económico de la isla que de emporio y centro distribuidor, se convierte en un centro eminentemente productor y exportador de sus propios productos, sin dejar de ser un importante puerto al que llevaban materiales de diversas y también lejanas procedencias, tanto para el consumo interno como para su comercialización en el litoral ibérico. El primer paso fue el ampliar las zonas de explotación de recursos, que hasta ahora se reducían, según los indicios arqueológicos, a las fértiles llanuras de los alrededores de la ciudad -el pla de Jesús, el pla de Vila y el pla de Sant Jordi i ses Salines-. En este sentido cabe mencionar un lecito de figuras negras, fechable en la primera mitad del siglo $\vee$ a.C., procedente del término de Santa Eulàlia des Riu (Trias, 1968: lám. CXLVII,3). A partir de estos momentos y de forma progresiva a lo largo del siglo $v$ a.C. la presencia de materiales ebusitanos, principalmente ánforas, irá en aumento en las costas peninsulares (Ramón, 1991 a: 144). También documentamos ahora los primeros contactos "pre-coloniales» con el mundo talayótico balear tanto en Mallorca (Guerrero, 1984 a: 12-13; ídem, 1985: 66) como en la propia Ibiza (Costa y Fernández, 1993 a). 

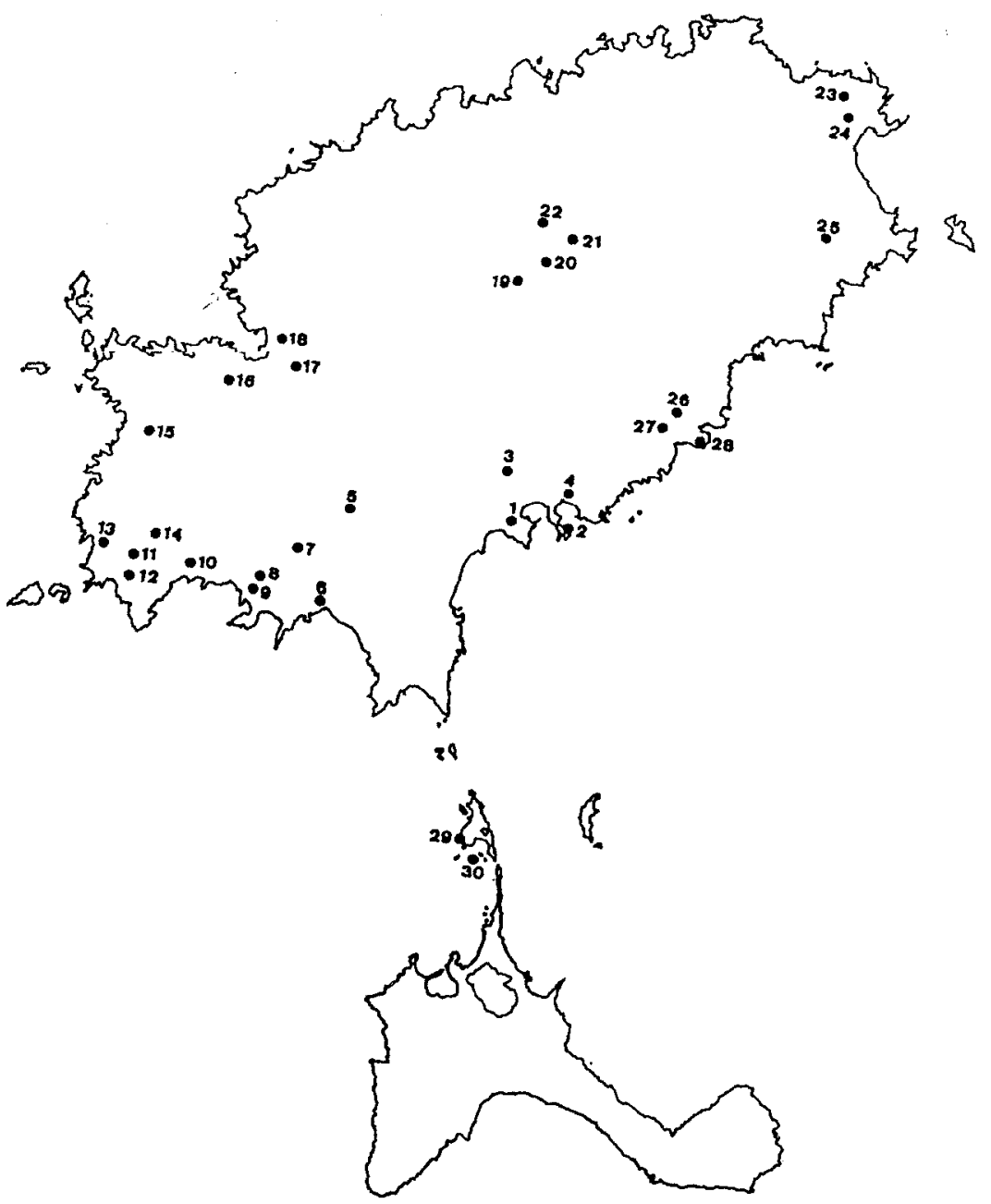

Figura 9. Mapa de lbiza y Formentera con los principales yacimientos púnicos: 1. Puig des Molins. 2. Illa Plana. 3. Puig d'en Valls. 4. Ses Torres (Talamanca). 5. Can Cardona. 6. Can n'Úrsul. 7. Sa Torrassa. 8. Ca na Jondala. 9. Cas Vildo. 10. Can Corda (puig des Collets). 11. Ses Pallisses de cala d'Hort (can Sorà). 12. Can Pep d'en Curt (coll de cala d'Hort). 13. Can Roques. 14. Can Berri d'en Sergent (cala Vedella). 15. Can Vicent Jeroni (cala Tarida). 16. Sa Barda. 17. Cas Jurat. 18. Can Rota. 19. Can Ferrer. 20. Ca n'Arnau. 21. Can Jai. 22. Can Guasch. 23. Es Culleram. 24. Can Pere Català des Port. 25. Can Marines. 26. Can Vic. 27. Ca na Polla. 28. Cap des Llibrell. 29. Espalmador. 30. Illa de s'Alga. 
Por otro lado, a nivel urbano podemos decir que el primitivo asentamiento fenicio debió de experimentar un notable crecimiento y, lo que es más importante, que la estructura urbana, ya establecida en la etapa anterior, consolida definitivamente el emplazamiento topográfico de sus principales elementos (figura 10): la población situada en la acrópolis, en la parte superior del puig de Vila, dominando la bahía; el puerto, al pie de la vertiente septentrional de la población, donde probablemente, además de instalaciones propiamente portuarias, habría también un área de mercado o barrio comercial (Ramón, 1985 a: 44), la necrópolis en la parte baja del puig des Molins, unos $500 \mathrm{~m}$. a Poniente de la ciudad, donde progresivamente los nuevos enterramientos púnicos invaden el antiguo cementerio fenicio, superponiéndose y cortando los viejos enterramientos de incineración; finalmente, un barrio artesanal de alfarerías (ibidem: 71-73), situado extramuros, principalmente entre las actuales calles de Vía Púnica y Aragón - es decir, al pie de la necrópolis y cerca del puerto-, cuya actividad está documentada en el taller llamado AL-2, el más antiguo conocido hasta la fecha, desde los últimos años del siglo VI a.C. (Ramón, 1981 c: 58-59), o tal vez ya en los primeros del v a.C. (ídem, 1991 a: 29-30). Uno de los santuarios se ubicaría también fuera del perímetro urbano, en el islote del centro de la bahía llamado actualmente s'illa Plana, si bien cabe pensar en la existencia de algún templo importante intramuros.

\section{EL DESARROLLO DE UNA SOCIEDAD PÚNICA EN IBIZA (CIRCA 450-350 A.C.)}

La nueva situación socio-económica creada en el período anterior, por la que la Ebusus phoenissa - parafraseando a Silio Itálico (Pun. 3, 362)se había convertido en la Ebusus poena, o - si se prefiere- en la E $\rho \varepsilon \sigma o s$

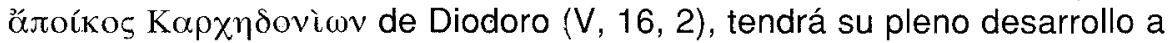
partir de mediados del siglo $v$ a.C.

Aún cuando, como hemos visto, los inicios deben remontarse al período anterior, es desde la segunda mitad del siglo $v$ a.C. cuando tenemos bien documentada la ocupación de toda la isla mediante el establecimiento de un buen número de asentamientos que a lo largo del siglo IV a.C. ocuparan todo el territorio rural ibicenco, tanto en el interior como en la zona costera (figura 9). Los más antiguos parecen ser los de la zona de Sant Agustí, en concreto sa Barda y cap des Salt, donde se documentan materiales de mediados o al menos de la segunda mitad del siglo v a.C. (Costa y Fernández, 1993 b). Estos establecimientos rurales 
(Ramón, 1985 a: 51-52; Gómez, 1986: 177-192), verdaderas unidades de hábitat y de producción, serán los centros encargados de la explotación de los recursos isleños, fundamentalmente agrícolas y ganaderos, constituyendo la infraestructura productiva que hará posible no sólo satisfacer las necesidades de abastecimiento de productos básicos de la población insular, sino también obtener los excedentes necesarios para el comercio exterior. De los más antiguos no se conocen las estructuras de hábitat y de producción, pues su existencia está documentada solamente por las pequeñas necrópolis, de hipogeos y/o fosas, que en cada asentamiento se situaban cerca del hábitat. En cuanto al ámbito urbano, será en este período que el antiguo asentamiento del puig de Vila experimentará un crecimiento que lo convertirá, definitivamente, en un verdadero centro urbano, uno de los pocos existentes entonces en esta área del Mediterráneo.

De esta manera queda establecido un patrón de asentamiento de la población de la isla que desde entonces se mantendrá, casi sin cambios, hasta tiempos recientes. Hay un único centro urbano, 'Iboshim ('ybshm), que concentrará principalmente la actividad comercial e industrial, así como - cabe suponerlo- el gobierno y la administración. El resto de la población está dispersa por todo el territorio insular, en un buen número de asentamientos rurales, dedicados básicamente a la producción. Ambos elementos - campo y ciudad - están pues estrecha e indisolublemente ligados, complementándose uno al otro, tanto social como económicamente (Costa y Fernández, 1990 a: XVIII). Así pues, Ibiza a partir de este momento modificará su estrategia económica y no se limitará a ser, como en la fase anterior - desde fines del siglo vII a fines del VI a.C.- , un centro redistribuidor de productos de otras procedencias, sino que iniciará también la exportación, cada vez a mayor escala, de sus propios productos, principalmente agrícolas (Costa, 1994: 114; Benito et alii, en prensa).

Otro aspecto que hay que destacar es que carecemos de evidencias de fabricación de cerámicas fuera del sector alfarero de la ciudad de lbiza, hasta por lo menos la época augustea (Ramón, 1981 c: 55-62; ídem, 1985 a: 71-73; ídem, 1991 a: 27-34; Fernández, Gómez y Gurrea, 1983), quizá con la excepción de los talleres para la fabricación de exvotos que debieron existir vinculados a los santuarios s'illa Plana y es Culleram. Este hecho, tal y como ha sido ya sugerido (Costa, 1994: 113; Benito et alii, en prensa) podría obedecer a un control por parte del poder político-económico - tal vez ejercido desde el templo principal-, que centralizaría en la ciudad toda la producción artesanal, desde la cerámica - vajilla de mesa, ánforas de almacenaje - al resto de la industria - metales, vidrios - y el comercio de 
productos suntuarios o de importación, siendo como era el principal $-\mathrm{y}$ tal vez único- puerto desde donde se canalizaría la exportación de los excedentes agrícolas y pesqueros y al que arribaban una amplia gama de productos provenientes del comercio exterior. De esa manera se potenciaba el papel de la ciudad como mercado y de esta forma los campesinos se veían obligados a recurrir a la ciudad para proveerse de aquellos bienes que no eran capaces de producir. De esta forma el control de los excedentes se realizaba de modo sutil pero efectiva y evitaba el tener que recurrir a otros métodos más explícitamente coercitivos.

Así, en la primera mitad del siglo iv a.C., nuestra ciudad se ha convertido ya en uno de los principales centros urbanos del Mediterráneo occidental, con una población de entre cinco y seis mil habitantes, según cálculos basados en el número de enterramientos de esta época en el puig des Molins (Ramón, 1985 a: 25-26; Costa, 1994: 104-113). En este sentido, resulta realmente sintomático que de entre todos los hipogeos excavados por C. Román entre 1921 y 1929 , el $92,36 \%$ se abran entre el 475 y el 350 a.C. (Fernández, 1992: II: 267; Costa y Fernández, 1995 a). El número de habitantes del ámbito rural es más difícilmente cuantificable en nuestro estado actual de conocimientos, pero no parece exagerado calcular en varios miles los pobladores del campo ebusitano.

En lo que se refiere a la producción local de cerámica (figura 12), éste es el período en el que se producen las formas más características de la cerámica púnico-ebusitana, si bien podemos distinguir dos momentos. Al primero, en la segunda mitad del siglo $v$ a.C., observamos como perduran las Eb. 12 y Eb. 61 pero, sobre todo en el último cuarto del siglo, aparecen nuevas formas tales como la Eb. 2 de tamaño grande, la Eb. $13 \mathrm{~A}$, la Eb. $30 \mathrm{~B}$, la Eb. 64 y probablemente también la Eb. 66. Al segundo, a partir del 400 a.C., desaparece la Eb. 30 B y presumiblemente la Eb. 66; la Eb. 2 grande es sustituida por la variante de pequeño tamaño, aparecen nuevas formas como la Eb. 1 y la Eb. 23 y perduran las Eb. 13, Eb. 61 y Eb. 64, pero experimentando una evolución en su morfología (Costa y Fernández, 1992: 333; Fernández, 1992, vol. II; Fernández y Costa, 1995).

La producción anfórica continua evolucionado con las PE-13, sucesoras de las PE-12, con las que lbiza iniciará su expansión comercial ya a una cierta escala, puesto que las encontramos en las Baleares, Ampurias y numerosos enclaves ibéricos, precisamente en los mismo lugares donde hallamos las PE-10 y PE-12 (Ramón, 1991 a), lo que hace razonable ver en ellas el resultado de la puesta en funcionamiento de los primeros asentamientos establecidos en el territorio rural de la isla (Costa, 1994: ; Benito et alii, en prensa). En este período no se documenta la producción de ningún 


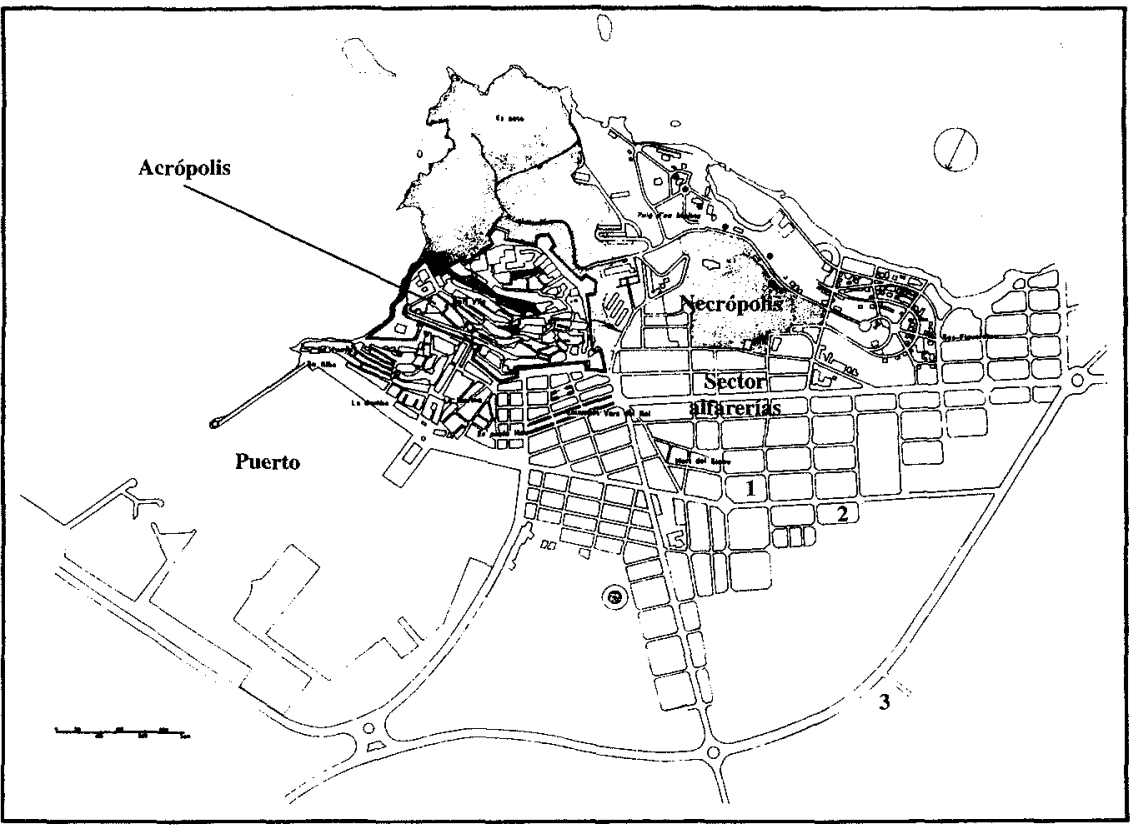

Figura 10. Plano de la ciudad de lbiza y de su entorno rural inmediato en época púnica, con la ubicación de los establecimientos rurales de es Paimer (1), Avda. d'Isidor Macabich, 50 (2) y sa Joveria (3) en el actual ensanche urbano.

tipo de la clase 2, pero en contrapartida, llegan a nuestra isla ánforas fenicio-occidentales Mañá-Pascual A 4, coríntias e ibéricas (Ramón, 1991 a: 146-147). Los contextos funerarios nos documentan también la llegada de cerámicas áticas sobretodo lékythos y lucernas, terracotas, huevos de avestruz, pequeños recipientes y otros elementos de pasta vítrea, amuletos y escarabeos, etc.

En cuanto al ritual funerario, la inhumación ahora sí es el procedimiento utilizado en exclusiva. El tipo de sepultura más común es el hipogeo, principalmente en la necrópolis del puig des Molins, donde cálculos recientes, tomando como punto de partida la planimetría parcial de un sector del yacimiento situado al Oeste del edificio del Museo Monográfico (Fernández, 1992: III: figura 3) nos permiten calcular la existencia de un hipogeo cada $15,7 \mathrm{~m}^{2}$, es decir, 636,9 hipogeos/Ha. Otras estimaciones en distintos puntos del yacimiento, han proporcionado valores comprendidos entre 13 y $19 \mathrm{~m}^{2}$, lo que hace que pueda aceptarse como válida una densidad media para todo el yacimiento de un hipogeo cada $15 \mathrm{~m}^{2}$, es decir, 
666,6 hipogeos/Ha. Así pues, si dividimos las cinco hectáreas que tendría la necrópolis en época púnica por $15 \mathrm{~m}^{2}$, obtendremos una cifra de 3.333 hipogeos, que creemos que debe estar próxima a la realidad. (Costa, 1994: 107). Sin embargo, a esta cantidad de sepulturas hemos de añadir los enterramientos en fosa, ya sean talladas en la roca o bien abiertas en la tierra, lo que incrementaría notablemente el número de enterramientos realizados en este yacimiento.

\section{EVOLUCIÓN DE LA IBIZA PÚNICA ENTRE MEDIADOS DEL SIGLO IN Y EL FINAL DE LA SEGUNDA GUERRA PÚNICA (CIRCA 350-200 A.C.)}

A partir de la segunda mitad del siglo IV a.C. el registro arqueológico es marcadamente desigual.

Por un lado, el barrio urbano de alfarerías ofrece unos ricos niveles arqueológicos y estructuras datables en este momento, que nos muestran una intensa actividad en la producción vascular (Ramón, 1981 c: 55-62; ídem, 1991 a: 27-34; Fernández, Gómez y Gurrea, 1983: 7-9). Es la época en que se fabrican las ánforas PE-14 y, aunque en mucha menor escala, las PE-22, la exportación masiva de las cuales supone un salto no sólo cualitativo sino también cuantitativo del comercio exterior ebusitano (Ramón, 1991 a: 147-152, mapa 2). Síntoma de esta proyección, especialmente importante a Baleares y Cataluña, pero también a todo el Levante peninsular, es la presencia constante de fragmentos anfóricos ebusitanos en los contextos arqueológicos de la época e incluso la aparición de un posible centro de producción de PE-14 tardías o PE-15 en Darró, cerca de Vilanova i la Geltrú, en la comarca del Garraf (López y Fierro, 1988: 61; ídem, 1994; Ramón, 1991 a : 80-81).

En las importaciones en cambio, a partir de mediados del siglo IV se observa la casi desaparición de las cerámicas áticas, que quedan prácticamente reducidas a unos pocos tipos de lucernas, e incluso estas sencillas piezas dejan de llegar a la isla en el siglo III a.C., ya que las piezas más tardías documentadas son lucernas de los tipos 25 A y B del Ágora de Atenas, de finales del siglo Iv (Sánchez, 1981: 307 y 309; ídem, 1985: 84).

En cuanto a la producción púnico-ebusitana de cerámica (figura 12), la segunda mitad del siglo IV, y más concretamente el último cuarto, marca la desaparición de algunas de las formas más características de la producción local de la etapa anterior, tales como la Eb. 1, Eb. 2, Eb. 23 y Eb. 64. En cambio, la Eb. 13 perdurará, y ya en el siglo III a.C. aparecen formas nuevas, tales como la Eb. 70, la Eb. 73, la Eb. 21, la Eb. 
76 y la Eb. 77 (Fernández, 1992: II: 282-283; Fernández y Costa, 1995), así como otras formas conexas que no están recogidas en la tipología de Tarradell y Font (Ramón, 1985 b: 52-58). También la coroplástica local, ahora con una marcada influencia siciliota, conocerá un notable desarrollo entre la segunda mitad del siglo iv y principios del III a.C. (Almagro, 1980).

En la necrópolis del puig des Molins, en cambio, se constata que alrededor del 350 a.C. baja radicalmente el número de hipogeos, ya que los que se abren entre el 350-325 a.C. es nada más un 9\% del total de los estudiados, y no hay ninguno cuya apertura pueda datarse con posterioridad al último cuarto del siglo iv a.C. Igualmente, el porcentaje de los que se reutilizan para nuevas deposiciones en el siglo y medio comprendido entre el 350 y el 200 a.C. es exactamente el $10 \%$. Así, pues, la creciente utilización que conoce la necrópolis hasta el 350 a.C., a partir del tercer cuarto del siglo Iv experimenta, de golpe, un descenso que, hoy por hoy, no estamos en condiciones de explicar satisfactoriamente, ya que el bajo porcentaje de utilización de hipogeos no se compensa con una mayor utilización de otros tipos de sepultura, al menos que se haya podido documentar. No obstante esto, creemos que no deben formularse hipótesis grandilocuentes que, como estamos viendo, la investigación puede en el futuro llenar lo que ahora parecen vacíos insalvables (Fernández, 1992: II: 271-273; Costa y Fernández, 1995 a).

Por otra parte, volviendo a la cuestión económica, alrededor del 300 a.C. Eivissa comenzó a acuñar su propia moneda (Campo, 1976: 88-90), o quizá algo después, pero en un momento que forzosamente ha de ser muy anterior a la Segunda Guerra Púnica, y por lo tanto situable dentro de la primera mitad del siglo III a.C. (Campo, 1993: 150-151; Eadem, 1994: 42-43). La moneda ebusitana se caracteriza por llevar, prácticamente en todas las emisiones de la ceca, la imagen del dios Bes, hecho que da consistencia a la hipótesis de que la leyenda que aparece en el reverso de las emisiones epigráficas más tardías -el plural 'ybshmpueda significar «islas de Bes» $y$, por tanto, que la figura del dios sea un símbolo parlante, tal como A. Judas ya intuyó en el siglo pasado (Judas, 1859: 647-648), pero que no solamente haría referencia a Ibiza, sino a ambas islas Pitiusas, Ibiza y Formentera, que eran denominadas conjuntamente Pityusai por los griegos y Ebusus por los romanos (Juan, 1988: 11-16). Las primeras emisiones ebusitanas encuadradas en el período I de Campo, entre c. 300 y el 214 a.C. (figura 13), suponen la mayor cantidad del numerario acuñado por la ceca, a pesar de que únicamente circule dentro de la isla (Campo, 1976: 37-41 y 93-95; ídem, 1987: 121). Estas primeras acuñaciones, de acuerdo con los nuevos 
datos, estaban compuestas por una fracción de plata, conocida por muy pocos ejemplares y dos valores de bronce (Campo, 1993: 149; Eadem, 1994: 39-40). Estos últimos presentan una gran variedad, si bien siguen el mismo sistema metrológico que Cartago y Gadir, es decir con una unidad de 9/9,50 gr. que después se devalúa ligeramente (Campo, 1976: 53-54; Eadem, 1987: 120; Eadem, 1993: 148; Eadem, 1994: 40).

El siglo III a.C está caracterizado por las dos primeras Guerras Púnicas. No obstante, el registro arqueológico en nuestra isla nos da muy poca información sobre este siglo. Es, paradójicamente, la presencia de materiales ebusitanos en yacimientos de fuera lo que nos ilustra principalmente sobre la situación de lbiza en estos momentos.

En lo que a Formentera se refiere, los materiales de esta época recogidos en superficie revelan una frecuente presencia púnica en la isla, y aunque hay autores que defienden su colonización por parte de ibicencos desde fines del siglo IV o inicios del III a.C. (González y Díes, 1993: 349), creemos que faltan pruebas de una población estable, y por tanto, de una verdadera colonización

Durante los dos primeros tercios del siglo III a.C. observamos que las ánforas PE-15 y PE-2:2 mantienen el flujo comercial de lbiza hacia el exterior, al menos hacia sus mercados tradicionales de las Baleares y al área ibérica catalana (Ramón, 1991 a: 149). Precisamente se ha interpretado el pecio menorquín de Binisafuller como un navío naufragado en la primera mitad del siglo III a.C. tal vez durante la Primera Guerra Púnica, que venía de Cataluña con un cargamento, contenido dentro de ánforas ibéricas de boca plana (Guerrero, Miró y Ramón, 1989: 115-125; ídem, 1991: 24-25). En opinión de J. Ramón, podría tratarse de un barco ibicenco que había vendido sus productos en las costas peninsulares y regresaba con un cargamento que probablemente podría ser trigo (Ramón, 1991 a: 148-149).

Igualmente, durante la Segunda Guerra Púnica, las ánforas PE-16 están presentes en numerosos yacimientos talayóticos e ibéricos, sobre todo catalanes y en menor escala valencianos (Ramón, 1991 a: 150-151). No obstante esto, no hemos de pensar que lbiza se mantuviera al margen del conflicto bélico, ya que no hay ninguna duda de que, como es lógico, nuestra isla estuvo en el bando cartaginés. Dos noticias de dos breves episodios de la guerra, que no tuvieron ninguna consecuencia en su desarrollo, nos lo confirman:

En el año 217 a.C. Ilega a la isla una flota romana al mando de Cneo Cornelio Escipión, con la finalidad de conquistar la ciudad. Después de dos días de asedio, viendo que la fuerte resistencia opuesta y las sólidas fortificaciones que protegían la ciudad suponían una conquista larga y costosa, los ro- 
manos saquearon las casas del campo, regresando después a sus naves con un botín muy superior al conseguido en la Península (T. Livio, XXII, 20, 7).

Doce años después, en el 205 a.C. llega una flota cartaginesa mandada por el almirante Magón, hermano de Aníbal, que es recibida muy amistosamente por los ibicencos que, además de proporcionarles abundantes suministros, le abastecen con armas y hombres para completar las tripulaciones de las naves, lo que le permitió continuar la campaña, marchando hacia las Baleares (T. Livio, XXVIII, 37, 3).

La numismática es también una fuente importante para conocer el papel de Ibiza en la Segunda Guerra Púnica. Parece que después de un tiempo de inactividad, la ceca vuelve a emitir moneda a partir del 214 a.C. y lo hace en cantidades importantes ya que la guerra impone a la isla unas necesidades financieras superiores, acuñando moneda de bronce y de plata (figura 13, Período II), que esta vez será acuñada en abundancia. En efecto, Ibiza hará cinco emisiones de moneda de plata (Campo, 1994: 44-45), que suponen casi el $8 \%$ de la plata acuñada por los cartagineses durante la guerra, cantidad incluso superior a la acuñada por Gadir (Campo, 1987:124-127).

Estos datos, juntamente con las referencias a las poderosas murallas que defendían la ciudad, al cuantioso botín obtenido por los romanos y al avituallamiento con armas y hombres de la escuadra de Magón, nos indican que, a pesar de la guerra, Ibiza mantenía un elevado potencial económico, que no sólo le permitía continuar e incluso potenciar sus intercambios con el exterior, sino también recuperarse de momentos desfavorables como fue el saqueo romano del 217 a.C.

\section{UN NUEVO STATU QUO: IBIZA ENTRE EL FIN DE LA SEGUNDA GUERRA PÚNICA Y LA CONQUISTA ROMANA DE LAS BALEARES (CIRCA 200-123 A.C.)}

Con la victoria romana se inicia una nueva etapa en que las formaciones sociales púnicas deben desarrollarse dentro de un nuevo marco de dominio económico y político. Pero, contrariamente a otros muchos autores, creemos que es erróneo hablar de época neo-púnica o, peor aún, de pervivencias púnicas dentro de la época romana. De acuerdo con los planteamientos de López Castro (1992 b y 1995) que compartimos, ello supone atribuir a las sociedades fenicio-púnicas un papel de meros receptores pasivos de una cultura supuestamente superior y negarles todo protagonismo en los procesos de transformación social, económica, política y cul- 
tural, que sufrieron durante el proceso que convencionalmente denominamos «romanización». A partir de la derrota de Cartago existe, pues, una situación de dominio por parte de Roma, que dará lugar a un proceso de transformación interna de las sociedades fenicio-púnicas, por el que sus estructuras fueron «disueltas» y substituidas por otras nuevas al integrarse plenamente en el Estado romano. Por ello preferimos hablar de un período púnico tardío en el que se desarrollaría dicho proceso, culminando con la definitiva incorporación de lbiza en el Imperio romano.

Aparentemente, resulta paradójico que después de la Segunda Guerra Púnica, lbiza - que, como hemos visto, no sólo había tomado partido por el bando cartaginés, sino que, además, contribuyó a sufragar los enormes gastos de la guerra - conozca una etapa de plenitud, tal vez la máxima de su historia, que durará los tres primeros cuartos del siglo II a.C. Los síntomas de este desarrollo son claros:

Por una parte, en el ámbito urbano se ha señalado una posible expansión del área urbana, ya que unas cisternas documentadas hace pocos años en el puig de Santa Llúcia y en sa Penya -que constituyen la prolongación septentrional del puig de Vila-, podrían datarse en la primera mitad del siglo ॥ a.C (Ramón, 1985 a: 69-70). Igualmente, no sólo se reemprende la producción de cerámica, sino que el sector industrial de alfarerías parece experimentar también un notable crecimiento que le llevará a alcanzar su máxima expansión (lbídem: 73).

Por otra parte, aunque una vez más hemos de remarcar la insuficiencia de nuestros conocimientos, derivada del todavía escaso número de excavaciones llevadas a cabo, parece que podemos afirmar que en el ámbito rural esta etapa se corresponde con un momento álgido de la explotación de los recursos agrícolas de la isla, puesto que en diversos yacimientos de la etapa anterior, que parece que hasta ahora eran bastante modestos, se detectan reestructuraciones y ampliaciones de sus instalaciones. Ses pallisses de Cala d'Hort, por ejemplo, conocerá ahora una de sus fases principales, convirtiéndose en un gran edificio de más de $800 \mathrm{~m}^{2}$, compuesto por diversas estancias que parecen articularse alrededor de un patio central abierto (Ramón, 1984: 14-15 y 36-37; ídem, 1985 a: 104-111). Asimismo, en otros yacimientos rurales que han sido objeto de excavación como can Corda (Ramón, 1985 a: 100-101, que lo llama es Collets) y can Fita (según comunicación personal de su excavador, R. González), se documenta también una etapa de crecimiento y desarrollo en la primera mitad del siglo II a.C.

Otros hechos significativos serían la ampliación de es Culleram, que en los dos primeros tercios del siglo II a.C. conocerá su período de apogeo, realizándose las obras documentadas arqueológicamente - y a las 
que podría referirse la inscripción tardo-púnica de la conocida plaqueta procedente de este santuario, según la lectura de Solá Solé (1951-52)-, que darían al santuario una estructura tripartita, como es característico de los santuarios de la antigüedad, con una primera sala construida con muros de piedra y con el suelo parcialmente tallado en la roca; una segunda sala dentro de la cueva, bajo una bóveda sostenida por columnas estalagmíticas, que hoy es un espacio exterior al encontrase hundida y arrasada casi por completo; y una tercera sala interior, en donde probablemente se situaría el sancta-santorum (Ramón, 1982 c y 1985 c). Igualmente, a principios del siglo ॥ a.C., se levantará un posible nuevo santuario que el excavador ha denominado cap des Llibrell (Ramón, 1985 a: 121-125), ubicado en el punto más alto del puig de ses Torretes, en cala Llonga, donde hay una visibilidad total sobre las costas orientales de la isla. Por eso no se descarta que este yacimiento, que posee una gran cisterna y sólidos paramentos murarios, tuviera también una función de lugar de vigilancia y control del entorno marítimo (Ramón, 1987-88).

En cuanto al comercio con el exterior, en concordancia con el desarrollo interno de la isla, la primera mitad del siglo II constituye un momento de apogeo, en particular en las factorías y enclaves ebusitanos en las costas baleares, a partir de las cuales se inunda de material ebusitano la práctica totalidad de poblados indígenas (Guerrero, 1984 a: 2529). Las PE-17, ánfora producida por los talleres ebusitanos a partir del segundo tercio del siglo ॥ a.C. (Ramón, 1981 c: 105-106; ídem, 1991 a: 112 j, presentan una dispersión equiparable, e incluso superior, a la de sus predecesoras PE-15 y PE-16. Las PE-24, que comienzan a fabricarse en el primer cuarto del siglo, imitan el perfil de las ánforas vinarias itálicas, las cuales a partir de ahora están cada vez más presentes en los mercados occidentales, hasta alcanzar un predominio absoluto, como nos muestran diversos pecios, de los que sin duda el de Gran Conglué I (Benoit, 1961) es el más conocido, juntamente con el de Antheor C (Joncheray, 1975) y otros. Partiendo de la hipótesis de que las PE-24 estaban destinados a contener vino (Ramón, 1981 c: 129), esta producción podría responder, en nuestra opinión, a un intento ebusitano de mantener una presencia efectiva en los mercados vinarios, en los que se habían intentado introducir desde hacía más de tres siglos con las producciones anfóricas precedentes de la clase 2 (Costa y Fernández, 1992: 342; idem, 1994: 23).

Es igualmente en el siglo II a.C. en que la moneda ebusitana, que comenzó a circular fuera de la isla en los últimos años del siglo III a.C., conocerá su máxima difusión, favorecida por el final de la Segunda Guerra Púnica, aunque deja de acuñarse plata y todas las emisiones desde ahora 

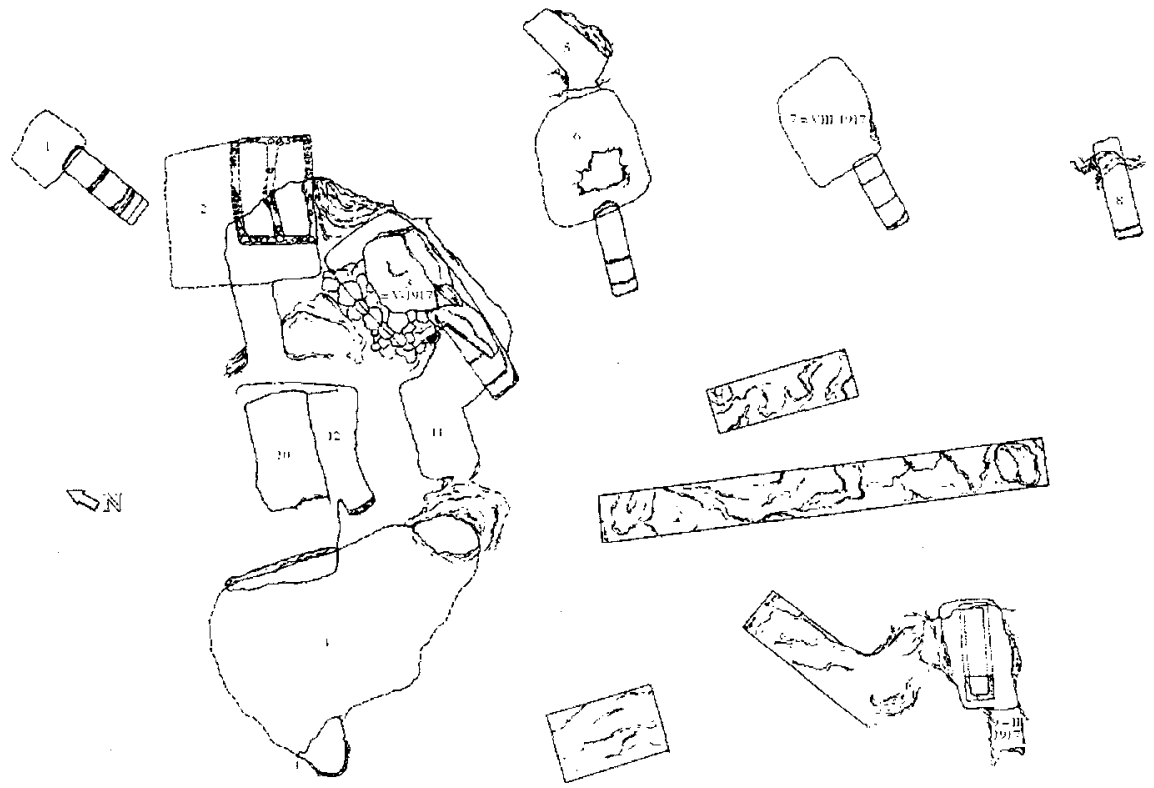

Figura 11. Necrópolis rural púnica de ses pallisses de cala d'Hort (Sant Josep). Planta parcial del yacimiento tras la campaña de 1995 (según Ramón, 1995).

se realizarán exclusivamente en bronce (Campo, 1993: 154; Eadem, 1994: 47). Hallazgos de numerario ibicenco están bien atestiguados en Baleares, Andalucía, el Sudeste y Levante peninsular, Cataluña, la Galia meridional, Cerdeña, Sicilia, Campania, Túnez, Argelia y Marruecos (Campo, 1983: 150-151) (figura 15). Por otra parte, en lbiza encontramos de esta época monedas de otras cecas púnicas como Cartago, fenicio-occidentales como Malaka, y sobre todo ibericas de Kese, Untikesken, Ikalkusken etc. (Fernández, 1976), pero hay que señalar que también aparecen ya las primeras monedas de la ceca de Roma (Ripollés, 1982: 464-467; Campo, 1983: 154).

Tal vez podemos ver en este desarrollo, no sólo la inercia de la dinámica generada en la etapa anterior (Ramón, 1991 a: 153), sino también, y sobre todo, un esfuerzo para rehacerse de los enormes dispendios causados por la guerra, aprovechando la oportunidad de una coyuntura favorable que permitiría mantener en plena actividad la compleja red de relaciones de Ebusus, activada a raíz de la Segunda Guerra Púnica (Costa y 
Fernández, 1994: 23). Sin embargo, dada la aparente discrepancia entre este desarrollo económico y la derrota púnica, la explicación se ha buscado en un texto de Plínio (Hist. Nat. III, 76-77) que dice que Ebusus era una civitas foederata de Roma (Gómez, 1989: 93). De este modo, la federación con los romanos explicaría el buen momento económico ebusitano de la posguerra.

Sin embargo, en nuestra opinión, no parece que realmente la explicación sea tan sencilla (Costa y Fernández, 1992: 342; ídem, 1994: 24). Lógicamente, el escritor latino se está refiriendo a la situación de su tiempo o de un poco antes, ya que, como es sabido, las noticias sobre Hispania de Plinio el Viejo están basadas principalmente en la documentación de comienzos de la época imperial, sobre todo de la obra de Agripa (Mangas, 1989: 161), aún cuando el autor tenía un conocimiento directo del país por haber sido procurador de finanzas de la Tarraconense. Podemos asumir, pues, que lbiza era una ciudad federada durante los tres primeros tercios del siglo I de la era. Desgraciadamente, Plinio no dice la fecha en que se estableció este foedus y, de hecho, este es uno de los problemas de la Historia Antigua de nuestra isla que la moderna investigación todavía tiene pendiente de solución. De entrada, no resulta convincente que, habiendo estado en el bando que pierde la guerra, Roma diese inmediatamente a Ibiza un pacto tan favorable, que en principio estaba reservado a los aliados o a premiar a algunas ciudades que habían tomado partido por la causa romana, como es el caso de Gadir que se entrega a los romanos en el 206 a.C., y no hay ninguna constancia de que entre el 205, en que llega al puerto ibicenco la escuadra de Magón, y el 201 a.C. en que se produce la derrota de Cartago, Ibiza cambiara su fidelidad a la causa púnica. Pero, por otro lado, nuestra isla no se vio afectada ni por la campaña del cónsul Catón, entre el 195 y el 193 a.C., para acabar con el levantamiento de los indígenas hispanos, ni por la Tercera Guerra Púnica, que acabará con el arrasamiento de Cartago en el 146 a.C., y también es evidente que en el 123 a.C. cuando se produce la conquista romana de las Baleares, si los ebusitanos no hubiesen estado en paz con Roma, las tropas de Quinto Cecilio Metelo no se hubiesen limitado a actuar en Mallorca y en Menorca. ¿Cómo entender, pues, esta situación aparentemente tan contradictoria?

Creemos que una explicación plausible es una previa deditio, es decir, una rendición incondicional y un completo sometimiento de lbiza al poder de Roma, puesto que cuando ésta se producía de manera voluntaria no suponía una pérdida de la libertad ni de la propia estructura de gobierno, pues Roma podía reconocer la comunidad dediticia como un sujeto autónomo de derecho, o incluso podía, posteriormente, establecer con ella un foedus 

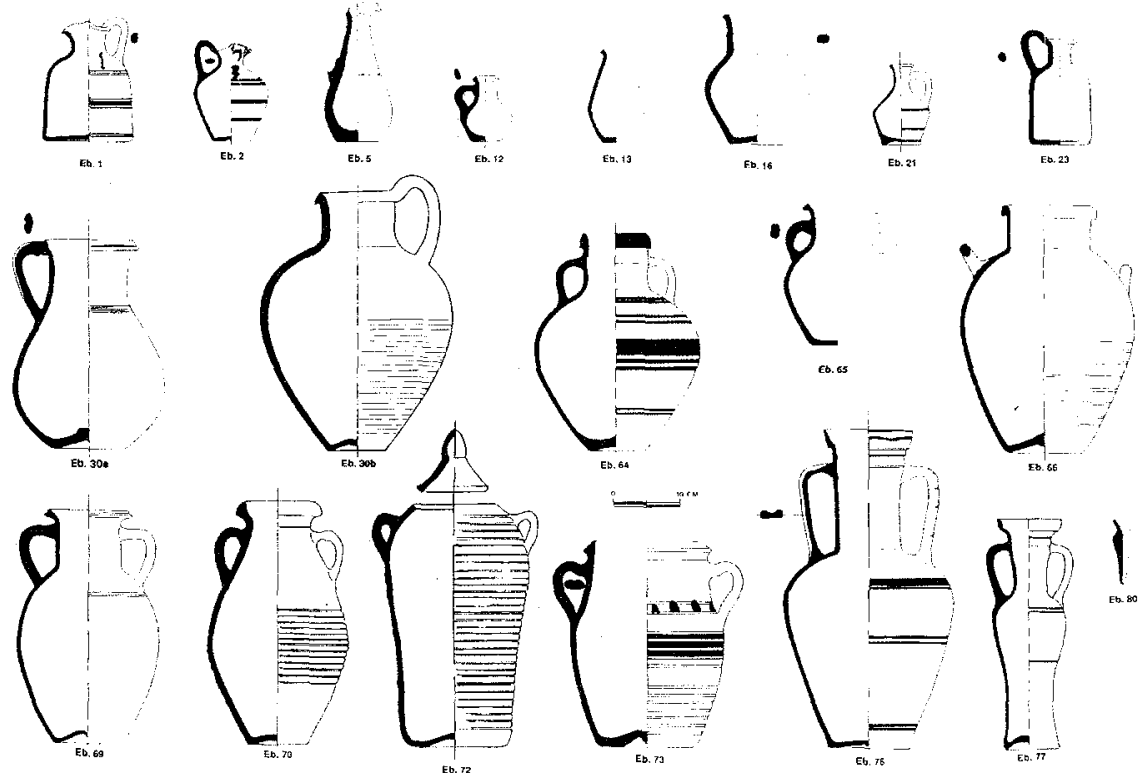

Figura 12. Tabla con las principales formas de la cerámica común púnico-ebusitana.

(Mangas et alii, 1982: 164). Nuestra hipótesis es que la deditio de lbiza se habría producido, probablemente, después de Zama y antes del 195 a.C. De esta manera, la federación habría tenido lugar más adelante, en una fecha por ahora imprecisable entre el siglo It a.C. y la época de Augusto en que, como hemos visto, el carácter de federada estaría confirmado por el texto de Plinio (Costa y Fernández, 1992: 343; ídem, 1994: 25).

De cualquier manera, si en la primera mitad del siglo $\|$ a.C. la economía ebusitana pudo alcanzar cotas tan altas de productividad e intercambio, esto fue posible, con o sin foedus, porque la actividad mercantil ibicenca no chocaba con los intereses romanos, al menos en aquellos momentos, cuando Roma se encontraba inmersa en empresas de mayor envergadura, tanto en el Mediterráneo oriental como en el occidental, donde había emprendido la organización territorial y administrativa de los extensos territorios hispanos recientemente conquistados. Bien al contrario, también los romanos podrían haber sacado provecho de los beneficios del comercio ebusitano, apropiándose de una parte de los réditos bajo la forma de impuestos o tributos, lo que no parece tan probable si lbiza ya fuese federada, puesto que - recordémoslo- las ciudades federadas estaban exentas de los impuestos ordinarios y fuera de la jurisdicción de los gobernadores provinciales (Costa y Fernández, 1994: 25-26). 

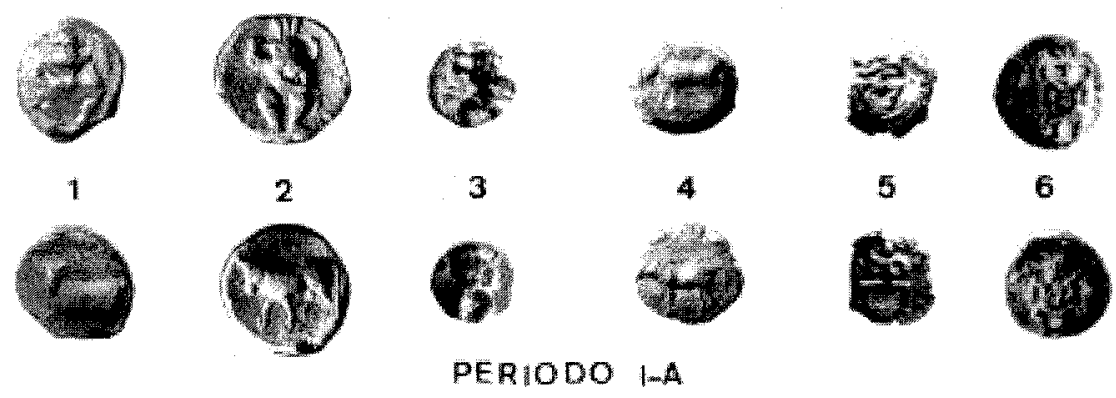

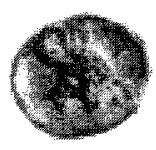

7
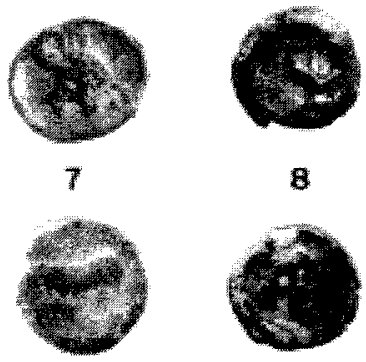

B
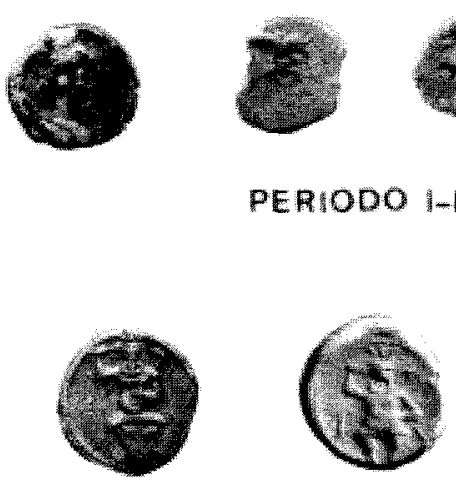

15

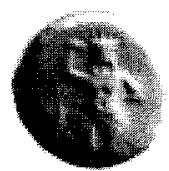

PERIODO II
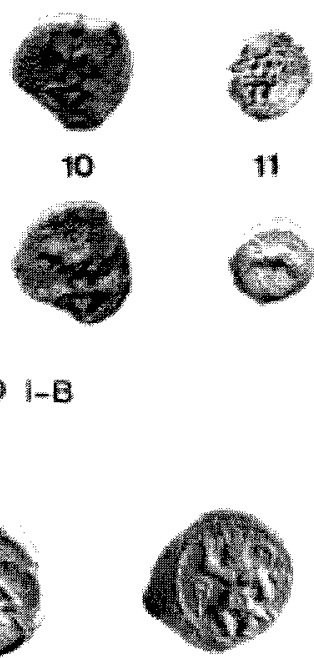

11

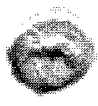

16
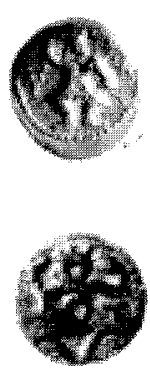

19
18

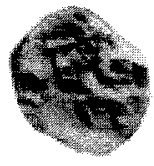

\section{1}

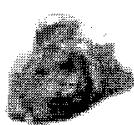

12

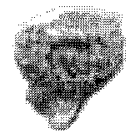

Figura 13. Moneda púnico-ebusitana: emisiones de los siglos "I y " a.C. (según Campo, 1993). 


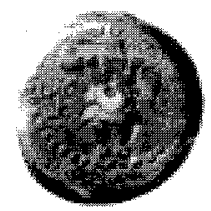

20
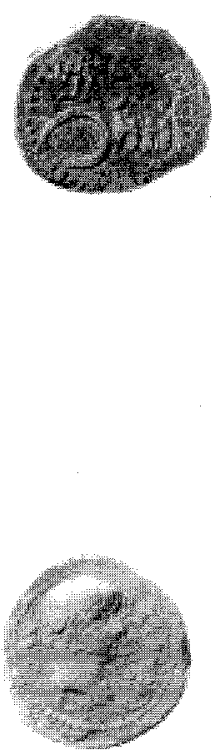

25

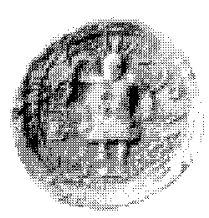

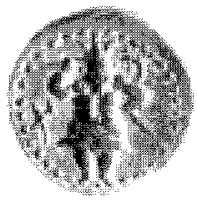

21
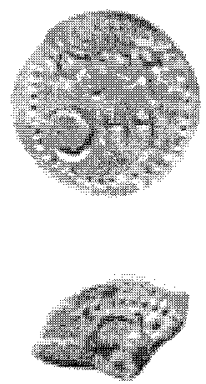

24

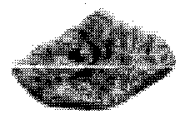

PERIODO

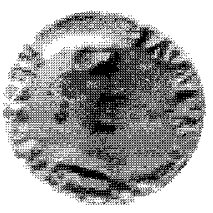

26
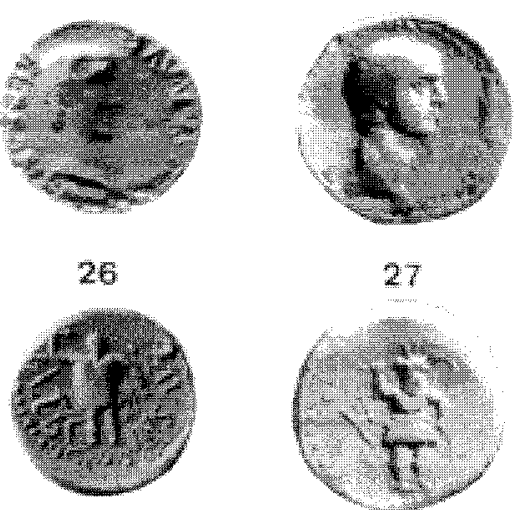

27

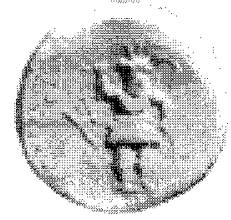

29
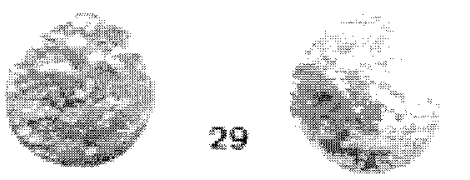

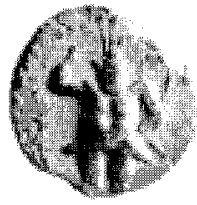

23

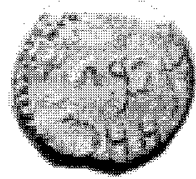

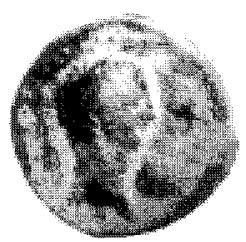

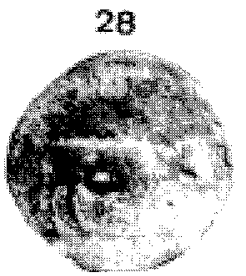

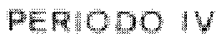

Figura 14. Moneda púnico-ebusitana: emisiones de los siglos । a.C. y I d.C. (según Campo, 1993). 
En cuanto a las prácticas funerarias de este período, las modernas excavaciones en la necrópolis urbana nos han documentado la práctica de la incineración juntamente con la inhumación. No obstante, hemos de decir que, de acuerdo con los datos reales, parece que la cremación ha sido muy sobrevalorada, ya que el número de incineraciones tardo-púnicas documentadas es escaso. A título de ejemplo podemos decir que en las excavaciones del solar $n^{\circ}$ 10-12 de la Calle León (Fernández et alii, 1984) en el estrato II se documentaron tres incineraciones datables en los siglos $111-$ II a.C. juntamente con los restos de varios centenares de individuos inhumados. Esto no impide que, aunque de manera minoritaria, la incineración se documente en enterramientos depositados ya directamente en la tierra, ya en el interior de cámaras de antiguos hipogeos, generalmente en el interior de jarras de cerámica púnico-ebusitanas, aún cuando no faltan ejemplos de la utilización de jarras púnicas norteafricanas, ibéricas e incluso talayóticas.

La inhumación es, con diferencia, el rito mayoritario y la forma habitual utilizada en los enterramientos de esta época es la deposición en fosas simples en la tierra, con frecuencia en ataúdes de madera (Costa y Fernández, 1995 a: 307). No obstante, se siguen reutilizando las cámaras de los antiguos hipogeos, si bien ahora las deposiciones se realizaran fuera de los sarcófagos de marés, junto a las paredes laterales de la cámara o en los espacios libres de ésta. Tenemos incluso documentado algún caso en el que para hacer sitio a nuevas deposiciones, los huesos de los enterramientos anteriores eran apilados junto al pozo o en algún rincón de la cámara (Costa, 1991: 46, lám. IV, 1; Fernández, 1992: II: 291). De todas formas, el número de hipogeos reutilizados en esta época supone el $18,32 \%$, lo que quiere decir que, aún cuando su reutilización no era un hecho extraño, tampoco estaba generalizado (Fernández, 1992: II: 292; Costa y Fernández, 1995 a: 307).

\section{UN PERIODO DE CRISIS Y TRANSFORMACIONES: IBIZA EN LA DESINTEGRACIÓN DE LA REPÚBLICA ROMANA (CIRCA 123-30 A.C.)}

A partir del último cuarto del siglo II a.C., la arqueología parece evidenciar un fuerte retroceso de la economía ebusitana, que acabará con la prosperidad que, como hemos visto, había disfrutado durante los últimos setenta y cinco años.

Por una parte, en el ámbito rural ibicenco se detecta una aparente crisis, que supondría que incluso algunos asentamientos sean abandonados, por 
ejemplo ses pallisses de cala d'Hort, que no presenta niveles arqueológicos correspondientes a este momento (Ramón, 1984: 36-37; ídem, 1985 a: 73; idem, 1991 a: 157). Por otra, parece que en la ciudad, a partir de finales del siglo 11 y durante todo el siglo I a.C., el sector alfarero se encuentra en un momento de baja actividad (Ramón, 1985 a: 73; ídem, 1991 a: 157).

Es también significativo que entre el 125 y el 75 a.C. parece que se producen una interrupción en las emisiones de la ceca ebusitana (Campo, 1976: 91), así como también se interrumpe la producción de las ánforas vinarias (Ramón, 1981 c: 125), ya que en un momento impreciso de finales del siglo II a.C. dejan de fabricarse las PE-24 sin dejar sucesoras directas, ya que las PE-25 y PE-26 no comenzarán a producirse hasta un año después (Ramón, 1991 a: 157-158). Además, se abandonan las factorías ebusitanas establecidas en Baleares, como muestran bien claramente las excavaciones de na Guardis (Guerrero, 1984 b: 210-211) y es Trenc, así como el yacimiento indígena de es turó de ses Beies (ídem, 1984 a: 28-29).

En definitiva, todo induce a relacionar este descenso con la conquista de Mallorca y Menorca por las tropas romanas al mando del cónsul Quinto Cecilio Metelo en el 123 a.C. que incidiría de manera negativa en el comercio exterior, privando a lbiza de sus mercados más importantes, al menos del balear, y consecuentemente a la economía interna ebusitana que ahora sí representaba una evidente competencia para los intereses de los romanos en Occidente, en donde habían conseguido consolidar el dominio sobre extensos y ricos territorios en Hispania, a los que ahora interesaba comenzar a hacer rentables mediante su explotación directa.

De todas formas, hay indicios de que pocos años después se experimenta una cierta recuperación, observable en la continuidad de uso del recinto del cap des Llibrell y de otros yacimientos (Ramón, 1991 a: 157). En este sentido, uno de los hechos más sintomáticos es el establecimiento de un enclave en Espalmador, islote casi unido al extremo Norte de Formentera, en el que en su parte sur hay un extenso yacimiento púnico. Se trata de un poblado que ocupa una considerable superficie, estimada en al menos unos veinticinco mil metros cuadrados, formado por un número superior al centenar de construcciones. Estas son unidades constituidas por diversas habitaciones de planta generalmente rectangular, si bien las hay de forma curvada casi semicircular, adosadas unas a las otras. El abundante material recogido en superficie, a la vez que permite datar el yacimiento entre el 125/100-50/30 a.C., indica además del hábitat, la práctica de actividades industriales, como la metalurgia (Ramón, 1985 a: 


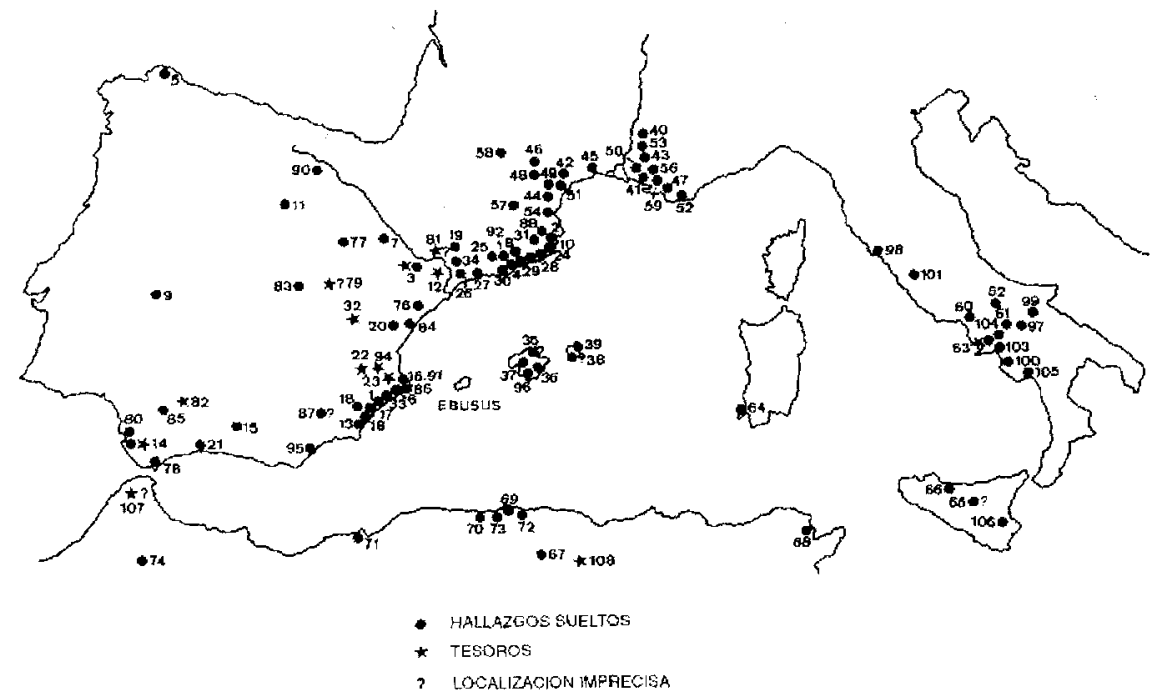

Figura 15. Mapa de hallazgos de moneda ebusitana (según Campo, 1993).

130-134). Cabe también señalar, que en la pequeña isla de s'Alga, frente a este poblado, hay también restos constructivos con materiales cerámicos de la misma época. No resulta fácil, pues, dada la falta de excavaciones y su carácter anómalo, dar una interpretación de estos enigmáticos yacimientos, que se establecen cuando se abandonan las factorías de las Baleares - lo que ha motivado que ambos hechos se hayan puesto en relación (Ibidem: 34 y 134)-, y parece que se abandonan cuando se produce el definitivo poblamiento de la isla de Formentera. A este respecto, recientemente se ha apuntado que el asentamiento de Espalmador hubiera podido ser la base portuaria de la actividad ebusitana en Formentera (González y Díes, 1993: 349).

El siglo । a.C. es poco conocido desde la perspectiva arqueológica. La presencia en nuestra isla de ciertas cantidades de materiales de procedencia itálica - cerámicas de barniz negro «campanienses» y ánforas vinarias - ilustran como la creciente hegemonía del comercio romano se va imponiendo. No obstante, hay' síntomas de una cierta recuperación de la crisis acaecida en el último cuarto del siglo $\|$ a.C. ya que el modelo ánfórico ebusitano que ahora está vigente - la PE-18- llega en la Península y Baleares, logrando una difusión creciente (Ramón, 1991 a: 158). Además, Ibiza vuelve a acuñar moneda, aunque de bronce y en un solo valor, de 6,37 gr, con símbolos y letras para diferenciar las emisiones, con la imagen en el anverso del dios Bes golpeando la serpiente, y en el reverso la 
leyenda 'ybshm en caracteres púnicos o neo-púnicos y el numeral 20-2010 (Campo, 1976: 45-48 Eadem, 1993: 157-158; Eadem, 1994: 48-50) (figura 14, Período II), cuya datación ha sido revisada y se ha situado entre post 91 a.C. y antes del 27 a.C. (Campo, 1993: 157).

Por otra parte, algunas noticias de las fuentes antiguas nos informan de algunos episodios de las Guerras Civiles que tuvieron lugar en Ibiza:

El año 82 a.C., Sertorio, que desde los territorios hispánicos se había enfrentado a la dictadura de Sila, desembarca en Ibiza y derrota a la guarnición romana de la isla, al mando de Annio. Pero, poco después, Annio regresa con una gran flota y cinco mil infantes. Sertorio le plantea una batalla naval, pero una fuerte tempestad dispersa sus naves y le obliga a huir, con grandes dificultades, con los barcos supervivientes (Plutarco: Sertorio, VII, 1; Annio Floro: Bellum Sertorianum, II, 10). En este sentido hemos de señalar que P.P. Ripollés interpreta la interrupción de emisiones de la ceca ebusitana a finales del primer cuarto del siglo । a.C. como una consecuencia de la crisis que sigue a la derrota de Sertorio, debido a las fuertes medidas tomadas por Roma (Ripollés, 1982: 467), aunque de aceptarse la nueva cronología propuesta por M. Campo para este grupo, este sugestivo argumento de Ripollés quedaría invalidado.

Treinta y cinco años más tarde, en el año 47 a.C. durante la guerra civil entre César y Pompeyo, Cneo Pompeyo, hijo de Pompeyo el Grande, se desplaza de África a Hispania llevando refuerzos. En el trayecto, ocupa Mallorca y Menorca sin dificultades, pero lbiza, que había tomado partido por la causa de Cesar, le opone una fuerte resistencia que, finalmente, conseguirá vencer. Pero habiendo caído enfermo, se establecerá con sus tropas en la isla durante algún tiempo (Dión Casio, XLIII, 29-30).

Cuando menos, el valor de estas noticias está en mostrar como en este período tan problemático para la República Romana, Ibiza, dado el valor estratégico de su posición en el campo de operaciones mediterráneas, es un enclave disputado por los distintos bandos en litigio. No sabemos si las guarniciones que ahora se establecen - la de Annio en el 81 a.C. y la que opuso resistencia a Pompeyo en el 47 a.C.- responden a hechos circunstanciales derivados de las operaciones bélicas de ambas guerras civiles, con las que se intentaría asegurar el control de la isla, o bien estaban permanentemente, y en tal caso ésta podría ser una de las condiciones impuestas en el foedus establecido con Roma. En cualquier caso, lbiza aparece plenamente inmersa en la problemática situación de la República, no sólo como escenario de determinados episodios bélicos, sino también tomando partido por uno u otro bando, lo que avala su progresiva integración en las estructuras romanas. 

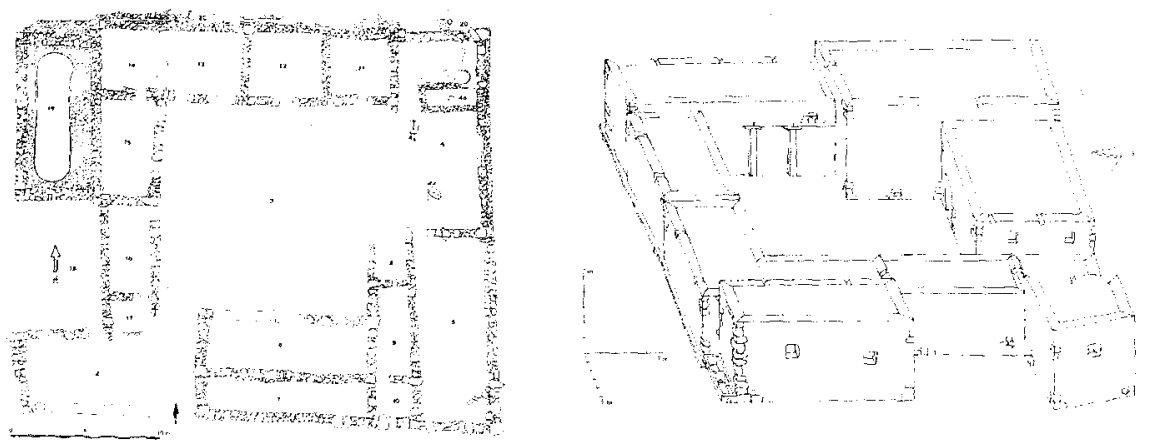

Figura 16. Establecimiento rural tardo-púnico y romano de ses pallisses de cala d'Hort (Sant Josep) en torno al cambio de era: (1) planta del yacimiento y (2) reconstrucción hipotética del mismo (según Ramón, 1995).

\section{HACIA LA DEFINITIVA INTEGRACION EN EL IMPERIO: DE LA EPOCA AUGUSTEA A LA MUNICIPALIZACIÓN (CIRCA 30 A.C.-74 D.C.)}

Acabados los enfrentamientos civiles, con los que también desapareció la República, y coincidiendo con el período de paz que llega a partir del principado de Augusto, Ibiza conocerá una nueva etapa de recuperación, e incluso de prosperidad, si bien no llegará a las cotas de desarrollo de mediados del siglo II a.C. En cualquier caso, los contextos arqueológicos del último cuarto del siglo । a.C. nos muestran un crecimiento de las producciones ebusitanas paralelo al crecimiento de las producciones hispánicas de la Bética y de la Tarraconense.

Los asentamientos rurales reemprenden su actividad, siendo reconstruidos y ampliados (figura 16), además de dotarlos con los medios técnicos de producción más avanzados de la época (trapeta, catilla, prensas de aceite del sistema de praelum, etc.). Además, el sector urbano de alfarerías incrementa su producción y, a la vez, surgen nuevos talleres en el área rural, como el de can Rova de Baix, en las afueras de la actual villa de Sant Antoni de Portmany (Ramón et alii, 1981: 215-259). Asimismo, Formentera se poblará ahora por ebusitanos que establecen un buen número de asentamientos rurales en la isla, de igual manera que habían hecho en Ibiza, cuatrocientos años antes. También se reemprenden las relaciones comerciales con el exterior, volviéndose a encontrar ánforas ibicencas en diferentes puntos de la costa peninsular y de las Baleares (Ramón, 1991 a: Mapa 3), donde las factorías ebusitanas vuelven a tener un corto periodo de funcionamiento, aunque a un bajo nivel de actividad, en cambio, las salinas de la Colònia de Sant Jordi conocerán ahora la fase de explotación más intensa (Guerrero, 1984 a: 31-33). 
Es en estas décadas anteriores al cambio de era cuando vemos que el proceso de romanización de la población pitiusa se va acentuando. Los materiales que aparecen en los contextos de hábitat y sobre todo en los funerarios nos muestran como las importaciones de este momento proceden muy mayoritariamente del ámbito romano, pues aparecen las primeras sigillatas itálicas (Fernández, Granados y González, 1992), vasos de paredes finas (Mayet, 1975), así como los ungüentarios piriformes de cerámica, mientras que los de vidrio comenzarán a ser masivamente utilizados en la primera mitad del siglo । d.C. (Miguélez, 1989: 69). Consecuencia de este predominio absoluto de los materiales romanos serán las versiones locales que los artesanos ibicencos, con seis siglos de tradición de imitar vasos extranjeros, harán de algunos de estos productos: las ánforas PE-25 que imitarían algunos aspectos formales de las Dressel 2-4 hispánicas, las PE-26 que parecen copiar las Dressel 7-11/Beltrán 1 (Ramón, 1991 a); diversas formas de vasos de paredes finas (Fernández y Granados, 1986: 51-56), y posiblemente también algunas formas de la sigillata itálica (Fernández, 1992: II: 206-207).

El panorama funerario de estos momentos y hasta la mitad del siglo II d.C., al igual que en los periodos inmediatamente anteriores, muestra la coexistencia de la incineración y la inhumación, pero ahora se "romaniza» la expresión material y formal del rito funerario. Las inhumaciones generalmente se realizan en los pozos de los antiguos hipogeos, ahora utilizados a manera de fosa. Los enterramientos de incineración pueden efectuarse en la tierra, bien directamente en un pequeño agujero, bien dentro de jarras de cerámica o urnas de vidrio, o pueden depositarse también en los hipogeos, cosa que parece menos frecuente. Los ajuares presentan notables diferencias tanto en cuanto a su cantidad como a su calidad (Fernández, 1992: II: 284-285; Costa y Fernández, 1995 a).

No obstante, a pesar de constatar que la dependencia de Roma es cada vez más estrecha, tanto en el aspecto material y económico, como en la política y la cultura, un hecho nos demuestra que Ibiza mantiene todavía su propia identidad: la acuñación de moneda. Efectivamente, en la primera mitad del siglo I d.C., la falta de numerario hace que la ceca reinicie su actividad emitiendo monedas con el busto del emperador - Tiberio y Calígulaen el anverso, pero conservando en el reverso la figura del dios Bes y la leyenda $y b s h m$ en caracteres neopúnicos, junto a la que presumiblemente es su traducción en caracteres latinos, INS AVG. Habrá dos últimas emisiones en época de Claudio, de mejor calidad que las dos anteriores pero con el hecho excepcional de ser anepígrafas, con el busto del emperador en el anverso $y$, en un caso la figura del dios Bes en el reverso, mientras que en el otro presentan un toro avanzando a derecha (figura 14, Período IV). Son acu- 
ñaciones reducidas, que circularán poco y parecen destinadas nada más a satisfacer las necesidades internas de la isla (Campo, 1976: 48-50 y 91; Eadem, 1987: 129-130; Eadem, 1993: 158-159; Eadem, 1994: 50-52).

El año 74 d.C., durante el reinado del emperador Vespasiano, se otorga a lbiza, juntamente con el resto de ciudades hispánicas, el ius Latii, es decir que nuestra ciudad pasa a regirse por el derecho latino, convirtiéndose en el Municipio Flavio Ebusitano, incluido en la provincia Tarraconense y dotado con una organización administrativa y con unos órganos de gobierno municipal ya perfectamente romanos, como nos confirman los testimonios epigráficos (Juan, 1988). Con la promulgación de su propia ley municipal, cuya fecha exacta nos es completamente desconocida, Ibiza pierde su carácter de foederata, y con ella su autonomía y singularidad, para integrarse, como un municipium más, en un imperio que por aquel entonces era ya muy extenso. De esta manera se culminaba el proceso de sustitución de las estructuras púnicas de la sociedad ebusitana por las nuevas que imponía su pertenencia al Estado romano.

Lógicamente, ello no afectaría por igual a toda la población. En la ciudad se documentan los elementos propios de la vida municipal, con una élite compuesta por algunas familias completamente romanizadas que acaparan las magistraturas municipales, se rodean de elementos materiales acordes con su condición -como esculturas, lápidas con inscripciones, etc- y practican el evergetismo, pero en los segmentos más populares y en el ámbito rural posiblemente los cambios tuvieran menor incidencia. No parece ilógico que el panorama que transmite San Agustín (Epist. ad Rom. 13) en el siglo $\vee$ d.C., sobre la pervivencia de la identidad púnica entre los campesinos norteafricanos, sea trasladable a otros muchos lugares del mundo púnico, entre ellos Ibiza. En cualquier caso, con la plena integración en el Imperio romano, los ebusitanos dieron un paso definitivo que abría una nueva etapa en su historia.

\section{BIBLIOGRAFÍA}

Alaminos, A. et alii. (1991): Algunas observaciones sobre el comercio colonial en la costa central y meridional de Catalunya en época arcaica. La presencia de material etrusco en la Península lbérica, págs. 275-294. Sezione di Studi Storici «Alberto Boscolo»-Universitat de Barcelona. Barcelona.

AlmagRo, M. (1960): Manual de Historia Universal. Vol. I. Madrid.

Almagro, Má. J. (1978): Revisión el recipiente de Naucratis de Ibiza. Trabajos de Prehistoria, 35, págs. 407-416. Madrid.

Almagro, Mª J. (1980): Corpus de las terracotas de lbiza. Biblioteca Praehistórica Hispana, vol. XVlll. Madrid.

AlvaR, J. (1991): La caída de Tiro y sus repercusiones en el Mediterráneo. La caída de Tiro y el auge de Cartago. V Jornadas de Arqueología Fenicio-Púnica (Ibiza, 1990). Trabajos del Museo Arqueológico de Ibiza 25, págs. 19-27. Ibiza. 
Alvar, J. (1995): De Argantonio a los romanos. La lberia protohistorica. Historia de España, 2. Historia 16. Madrid.

ALVAR, J. y G. WAGNeR, C. (1988): La actividad agrícola en la economía fenicia de la Península Ibérica. Gerión 6, págs. 170-185. Universidad Complutense. Madrid.

ARteaga, O. (1976-78): Problemática general de la iberización en Andalucía Oriental y en el Sudeste de la Península. Simposi Internacional "Els Orígens del món Ibèric" (BarcelonaAmpurias, 1977). Ampurias, 38-40, págs. 23-60. Barcelona.

ARTEAGA, O. (1987): Perspectivas espacio-temporales de la colonización fenicia occidental. Ensayo de aproximación, en A. Ruiz y M. Molinos (coord.): Iberos. Actas de las I Jornadas sobre el Mundo Ibérico (Jaén, 1985), págs. 205-228. Ayuntamiento de Jaén. Junta de Andalucía. Jaén.

ARTEAGA, O.; PAdRó, J. y SANMARTí, E. (1978): El factor fenici a les costes catalanes i del Golf de Lió. Els pobles pre-romans del Pirineu. $2 n$ Col'loqui Internacional d'Arqueologia de Puigcerdà (Juny, 1976), págs. 129-136. Institut d'Estudis Ceretans. Puigcerdà.

ARTEAGa, O.; PADRó, J., y SANMARTí, E. (1986): La expansión fenicia por las costas de Cataluña y del Lenguadoc, en Olmo Lete, G. de y Aubet, $\mathrm{M}^{a} \mathrm{E}$. (eds.): Los fenicios en la Península lbérica, págs. 303-314. Ed. Ausa.Sabadell.

ArteagA, O., y Serna, M. R. (1975): Los Saladares-71. Noticiario Arqueológico Hispano, Arqueología, 3, págs. 7-141. Madrid.

ASENSIO, D. et alii (1996): El poblament de les comarques del curs inferior de l'Ebre durant el Bronze final i la Primera Edat del Ferro, en ROVIRA, J. (ed.): Models d'ocupació, transtormació i explotació del territori entre el 1600 i el 500 a.n.e. a la Catalunya Meridional i zones limitrofes de la depressió de l'Ebre (Taules Rodones d'Arqueologia, Sant Feliu de Codines). Gala 3-5 (1994-1996).

AuBET, Ma E. (1976-78): La cerámica a torno de la Cruz del Negro (Carmona, Sevilla). Simposi Internacional "Els Orígens del món lbèric (Barcelona-Ampurias, 1977). Ampurias 38-40, págs. 267-287. Barcelona, 1976-78.

AuBET, M.E. (1987): Tiro y las colonias fenicias de Occidente. Ed. Bellaterra. Barcelona.

Aubet, Ma. E. (1992): Nuevos datos arqueológicos sobre las colonias fenicias de la bahía de Málaga. Lixus (Larache, 8-11 novembre 1989), págs. 71-78. École Française de Rome.

Aubet, Mª. E. (1993): El comerç fenici i les comunitats del Ferro a Catalunya. El poblament ibèric a Catalunya. Laietània 8, págs. 23-40. Museu Comarcal del Maresme, Secció Arqueològica. Mataró.

AUBET, $M^{a}$. E. (1995): El comercio fenicio en Occidente: balance y perspectivas. I Fenici: ieri, oggi, domani. Ricerche, scoperte, progetti (Roma, 3-5 marzo, 1994), págs. 227-243. Academia Nazionale dei Lincei-Consiglio Nazionale delle Ricerche. Roma.

BAQUÉs, L. (1975): Escarabeos egipcios de lbiza. Ampurias 36-37, págs. 87-146. Barcelona.

Barceló, P. A. (1985): Ebusus: ¿Colonia fenicia o cartaginesa? Gerión 3, págs. 271-282. Universidad Complutense. Madrid.

Barceló, P. A. (1986): El comienzo de la presencia cartaginesa en lbiza. Studia Histórica, Vol. IIIII nº 1, págs.73-80. Salamanca, 1984-85.

BARCELÓ, P. A. (1988): La relevancia comercial de la presencia cartaginesa en lbiza, en T. Hackens (ed.): Navies and Commerce of the Greeks, the Carthaginians and the Etruscans in the Tyrrhenian Sea. Acts of the European Symposium held at Ravello (January 1987). Pact 20-11.1, págs. 125-140.

BENITO, N. et alii (en prensa): Ibiza púnica: la colonización agrícola. Algunos planteamientos para su estudio. IV Congreso Internacional de Estudios Fenicios y Púnicos (Cádiz, 1995)

BENOIT, F. (1961): L'épave du Grand-Conglué a Marseille. Supplement à Gallia XIV.

CABRERA, P. (1985): Nuevos fragmentos de cerámica griega arcaica en Huelva. Ceràmiques gregues i helenistiques a la Peninsula lbèrica. Taula Rodona 75 Aniversari de les excavacions d'Empuries (Empúries, 1983). Monografies Emporitanes VII, págs. 43-57. Barcelona.

CABRERA, P. (1986): Los griegos en Huelva: Los materiales griegos. Actas del Congreso a Homenaje a Luis Siret» (1934-1984). Cuevas del Almanzora (Junio 1984), págs. 575-583. Madrid.

CABrera, P. (1988-89): El comercio foceo en Huelva: Cronología y fisionomía. Huelva Arqueológica, X-XI, 3, págs. 41-100. Huelva.

CAMPO, M. (1976): Las monedas de Ebusus. A.N.E. Barcelona.

CAMPO, M. (1983): Las relaciones de Ebusus con el exterior a través de los hallazgos monetarios (siglos III-I a.C.). Atti del / Congresso Internazionale di Studi Fenici e Punici, vol. I, págs. 146156. Roma. 
CAMPO, M. (1987): La ceca de Ebusus: Producción y función. Actes du Colloque International: Rythmes de la Production Monétaire, de l'Antiquité à nos jours (Paris, 1986). Numismatica Lovaniensia 7, págs. 119-132. Louvain-La-Neuve.

CAMPO, M. (1993): Las monedas de Ebusus. Numismática Hispano púnica. Estado actual de la investigación. VII Jornadas de Arqueología Fenicio-Púnica (Ibiza, 1992). Trabajos del Museo Arqueológico de lbiza, 31, págs. 147-168. lbiza.

CAmpo, M. (1994): Les monedes de l'Eivissa Púnica. La moneda a l'Eivissa púnica. Sa Nostra, págs. 39-98. Palma de Mallorca.

Corzo, R. (1988): Los fenicios, señores del mar. Historias del Viejo Mundo nº 8. Historia 16. Madrid.

CostA, B. (1986): Las excavaciones arqueológicas realizadas en la Vía Romana: Can Partit. Anuario de lbiza y Formentera V, págs. 99-103. Ibiza.

Costa, B. (1988): Los enterramientos de Can Partit (Necrópolis Puig des Molins), Ibiza (Baleares): Una pérdida irreparable del Patrimonio Arqueológico. Espacios Europeos 6, págs. 52-56. Año II, Marzo. Madrid.

CostA, B. (1991): Las excavaciones arqueológicas en el solar $n^{2} 38$ de la Via Romana (Can Partit). Nuevos datos para el conocimiento de la Necrópolis del Puig des Molins, en I-IV Jornadas de Arqueología Fenicio-Púnica (Ibiza, 1986-89). Trabajos del Museo Arqueológico de Ibiza, 24, págs. 29-57. Ibiza.

CostA, B. (1994): Ebesos, colonia de los cartagineses. Algunas consideraciones sobre la formación de la sociedad púnico-ebusitana. Cartago, Gadir, Ebusus y la influencia púnica en los territorios hispanos. VIII Jornadas de Arqueología Fenicio-Púnica (Ibiza,1993). Trabajos del Museo Arqueológico de Ibiza, 33, págs. 75-143. Ibiza.

Costa, B., y Fernández, J.H. (1988): Les Phéniciens à Ibiza. Les Phéniciens à la Conquéte de la Méditerranée. Dossiers d’Histoire et Archeologie nº 132, págs. 80-81. Novembre. Dijon.

Costa, B., y FERnANDEZ, J.H. (1990 a): 'Iboshim: Els orígens fenicio-púnics de la ciutat d'Eivissa. Testimonis de la nostra Història. Exc. Ajuntament d'Eivissa. Eivissa.

Costa, B., y Fennández, J.H. (1990 b): El patrimonio arqueológico de las islas Pitiusas. Consideraciones en torno a la problemática de su defensa y conservación. Actes de/ I Congrès "El nostre patrimoni cultural: Base judírica per a la seva defensa".(25-28 Febrer, 1990). Bolletí de la Societat Arqueològica Lul.liana, 46, págs. 279-297. Palma de Mallorca.

Costa, B., y FERnándeZ, J.H. (1992): Les Illes Pitiüses: De la Prehistòria a la fi de l'època púnica. La Prehistòria de les Illes de la Mediterrània Occidental. X Jornades d'Estudis Històrics Locals, pags. 277-355. Institut d'Estudis Baleàrics. Palma de Mallorca.

CostA, B., y FERNÁNDEZ, J.H. (1993 a): Ibiza en época arcaica (c. 650-475 a.C.): fundación feniciacolonia cartaginesa. Estado actual de la cuestión. Rev. Empúries 48-50, 1 (1986-1989), págs. 254-263. Barcelona.

COSTA, B., y FernáNDEZ, J.H. (1993 b): La forma Eb. 2 de la ceràmica púnico-ebusitana. Homenatge a Miquel Tarradell. Estudis Universitaris Catalans vol. XXIX, págs. 345-366. Curial Edicions Catalanes. Barcelona.

COSTA, B., y FERNÁNDEZ, J.H. (1994): 'YBSHM (Eivissa). Història d'un centre púnic emissor de moneda. La moneda a l'Eivissa púnica, págs. 13-35. Sa Nostra, Palma de Mallorca.

COSTA, B., y FERNÁNDEZ, J.H. (1995 a): Las fases fenicio-púnicas de utilización de la necrópolis del Puig des Molins. II/e. Congrés International des Etudes Phéniciennes et Puniques (Tunis, 1991). Túnez.

COSTA, B., y FERNÁNDEZ, J.H. (1995 b): La arqueologia fenicio-púnica en Ibiza: reflexiones sobre noventa años de investigaciones (1903-1993). I Fenici: ieri, oggi, domani. Ricerche, scoperte,progetti (Roma, 3-5 marzo, 1994), págs. 375-394. Academia Nazionale dei Lincei - Consiglio Nazionale delle Ricerche. Roma.

Costa, B., y FERNÁNDEZ, J.H. (en prensa): El establecimiento de los fenicios en Ibiza: algunas cuestiones actualmente en debate. IV Congreso Internacional de Estudios Fenicios y Púnicos (Cádiz, 1995).

Costa, B.; Fernández, J.H.; De Hoyos, R. (1996): La Ley 16/1985 y la defensa del Patrimonio Arqueológico en lbiza: El caso de can Partit, en Homenaje a Manuel Fernández Miranda Complutum Extra 6, vol. II, págs. 369-381. Madrid.

Costa, B., y Fernández, J.H.; GómEz, C. (1991): Ibiza Fenicia: La primera fase de la colonización de la isla (siglos vil y vi a.C.). Il Congresso Internazionale di Studi Fenici e Punici. (Roma, 9-14 Novembre 1987). Vol. II, págs. 759-795. Roma. 
Costa, B. y Gómez, C. (1987): Las importaciones cerámicas griegas y etruscas en Ibiza. Mélanges de la Casa de Velázquez, t. XXIII, págs. 31-56. París.

FantaR, M. (1993): Carthage. Approche d'une civilisation. 2 t. Alif-Les Éditions de la Mediterranée. Tunis.

FANTAR, M. (1994): De Carthage à Carthagène, en González Blanco et alii (coord.): El mundo púnico. Historia, sociedad y cultura (Cartagena, $17-19$ de noviembre de 1990), págs. 87-96. Murcia.

Fernández, J. H. (1976): La circulación monetaria ibérica en lbiza. Il Congreso Nacional de Numismática (Salamanca, 1974). Numisma, 138-143, págs. 49-57. Madrid.

FernándeZ, J. H. (1992): Excavaciones en la necropolis del Puig des Molins (Eivissa). Las campañas de D. Carlos Román Ferrer: 1921-1929. 3 vols. Trabajos del Museo Arqueológico de Ibiza, núms. 28-29. Ibiza.

FERNÁNDEZ, J.H. y COSTA, B. (1995): La cerámica común púnico-ebusitana: formas principales y cronología. IIle. Congrés international des Etudes Phéniciennes et Puniques. (Tunis, 11-16 novembre 1991), vol. II, págs. 10-25. Tunis.

FERNÁNDEZ, J.H. y COSTA, B. (en prensa): La investigación fenicio-púnica en lbiza a principios de los años noventa. IV Congreso Internacional de Estudios Fenicios y Púnicos (Cádiz, 1995).

Fernández, J.H., y Granados, J.O. (1986): Producción de paredes finas en Ebusus. Actes du Congres de Toulouse (9-11 Mai 1986). Societé Francaise d'Etude de la Ceramique Antique en Gaule. Marseille.

FERNÁNDEZ, J.H.; GÓMEZ, C., y GuRREA, R. (1983): Excavacions arqueològiques a la ciutat d'Eivissa. Rev. Eivissa $\mathrm{n}^{\mathrm{0}} 14$ (3 $3^{\mathrm{a}}$ època), págs. 7-9. Eivissa.

FERnÁNDEZ, J.H.; Gómez, C., y GuRREA, R. (1984): La premiére periode de la colonisation punique à Ibiza. The Deya Conference of Prehistory: Early Settlement in the Western Mediterranean Islands and the Peripheral Areas. B.A.R. International Series 229, vol. III, págs. 785-796. Oxford.

Fernández, J.H., Granados, J.O., y GonzÁlez, R. (1992): Marcas de terra sigillata del Museo Arqueológico de Ibiza. Trabajos del Museo Arqueológico de Ibiza, 26. Ibiza.

FERNÁNDEZ, J.H. et alii (1984): Excavaciones de urgencia en Eivissa. Excavaciones arqueológicas en la C/ León 10-12. Ibiza.

FERNÁNDEZ JuRADO, J. (1984): La presencia griega arcaica en Huelva. Monografías Arqueológicas, 1. Huelva.

FERRÓN, J. (1969): Les statuettes au tympanon des hypogées puniques. Antiquités Africaines tome 3, págs. 11-33. Éditions du C.N.R.S. Paris.

Frutos, G. DE (1991): Cartago y la política colonial. Los casos norteafricano e hispano. Ed. Gráficas Sol. Écija.

García y BELLIDO, A. (1952): La colonización púnica, en Historia de España dirigida por Menéndez Pidal, vol. I, 2, págs. 493-680. Madrid.

García Menárguez, A. (1994): El Cabezo Pequeño del Estaño, Guardamar del Segura. Un poblado protohistórico en el tramo final del río Segura, en González Blanco et alii (Coord.): El mundo púnico. Historia, sociedad y cultura (Cartagena, 17-19 de noviembre de 1990), págs. 269-280. Murcia.

Gómez, C. (1983): Urna de orejetas con incineración infantil del Puig des Molins. Trabajos del Museo Arqueológico de Ibiza, 9. Ibiza

GómEz, C. (1986): Asentamientos rurales en la Ibiza púnica. Aula Orientalis vol. III, págs. 177179. Barcelona.

Gómez, C. (1988): Novedades de Arqueología fenicio-púnica en Ibiza. Archivo Español de Arqueologia,61, págs. 226-229. Madrid.

Gómez, C. (1989): L'île d'ibiza a l'époque des Guerres Puniques. Punic Wars. Studia Phoenicia X, págs. 85-97. Leuven.

GÓMEZ, C. (1991 a): La fondation phénicienne d'lbiza et son développement aux VII et Vle s. av. J.C. II Congresso Internazionale di Studi Fenicie Punici. (Roma, 9-14 Novembre 1987) Vol. II, págs. 109-112. Roma.

GómEZ, C. (1991 b): Kantharos, aryballos y esfinge de hueso: Reflexiones a partir de los materiales etruscos en Ibiza. La presencia de material etrusco en la Península lbérica, págs. 295308. Sezione di Studi Storici «Alberto Boscolo»-Universitat de Barcelona. Barcelona.

Gómez, C. (1991 c): Ibiza en época arcaica: Estado actual de la investigación. I-IV Jornadas de Arqueología Fenicio-Púnica (Ibiza, 1986-1989). Trabajos del Museo Arqueológico de Ibiza, 24, págs. 21-28. Ibiza. 
Gómez, C. (1992): L'île d'lbiza dans le commerce en Mediterranée Occidentale a l'epoque archaiche: Quelques donées nouvelles. Colloque de Louvain (mai 1987). Studia Phoenicia I $X$, págs. 299-309. Louvain.

Gómez, C. (1993): Die Phönizier auf Ibiza. Madrider Mitteilungen, 34, 83-107. Verlag Philipp von Zabern. Mainz.

GómEZ, C. (1995): The colonization of Ibiza and Formentera (Balearic Islands, Spain): some more islands out of the stream?, en Cherry, J.F. (Ed.): Colonization of Island. World Archeology, vol. $26 n^{\circ} 3$, págs. 442-455. Routledge.

GómEz, C. (1996): Quelques réflexions sur les premiers établissements phéniciens à Ibiza. Omaggio a $S$. Moscati. Roma.

Gómez, C. y SAN Nicolás, P. (1988): La Prehistoria de Ibiza y Formentera. Estado actual de la investigación. Trabajos de Prehistoria, Vol. 45, págs. 201-228. Madrid.

GÓMEZ, C. et alij (1990): La colonización fenicia de la isla de lbiza. E.A.E. n 157. Madrid.

GonzÁleZ, A. (1985): Sobre unos elementos materiales del comercio fenicio en tierras del Sudeste peninsular. Lucentum IV, págs. 97-106. Universidad de Alicante. Alicante.

GonzAlez, A. (1990): Nueva luz sobre la Protohistoria del Sudeste. Universidad de Alicante.

GonzALEZ, A. (1991): La presencia fenicia en el Levante Penínsular y su influencia en las comunidades indígenas. I-IV Jornadas de Arqueología Fenicio-Púnica (Ibiza, 1986-1989). Trabajos del Museo Arqueológico de Ibiza, 24, págs. 109-118. Ibiza.

GonZÁLEZ, A. (1993): Quince años de excavaciones en la ciudad protohistórica de Herna (La Peña Negra, Crevillente, Alicante). Saguntum, 26, págs. 181-188. Universitat de València. Valencia.

GonzÁlez, A.; García, A. y Ruiz, E. (1997): La Fonteta. Una ciudad fenicia en Occidente. Revista de Arqueología, 190 (febrero), págs. 8-13. Madrid.

GONZÁLEZ, R. y DiES, E. (1993): Evolución de la ocupación del suelo de Formentera: Épocas púnica y romana. Cuadernos de Prehistoria y Arqueología Castellonense, 15, págs. 335-373. Castellón, 1990-1991.

Gran-Aymerich, J. (1991): Malaga phénicienne et punique. Editions Recherche sur les Civilisations. Paris.

Gras, M.; Rouillard, P., y Teixidor, J. (1991): El universo fenicio. Biblioteca Mondadori. Madrid.

GUERRERO, V.M. (1984 a): La colonización púnico-ebusitana de Mallorca. Estado de la cuestión. Trabajos del Museo Arqueológico de Ibiza, 11. lbiza.

Guenafro, V.M. (1984 b): El asentamiento púnico de Na Guardis (Mallorca). E.A.E.n 133. Ministerio de Cultura. Madrid.

GueRrero, V.M. (1985): Indigenisme i colonització púnica a Mallorca. Ses Salines.

Guerrero, V.M.; Miró, J., y RAmón, J. (1989): L'épave de Binisafuller (Minorque). Un bateau de comerce punique du llième. siècle av. J.C. Punic Wars (23-26 November 1988) Studia Phoenicia, $X$, Orientalia Lovaniensia Analecta, 33, págs. 115-125, Leuven.

Guerrero, V.M.; Miró, J., y Ramón, J. (1991): El pecio de Binisafuller, mercante púnico del siglo II! a.C. Rev. Meloussa, 2, págs. 9-30. Maó

GurREA, R., y RAMón, J. (en prensa): Excavaciones arqueológicas en la acrópolis de Eivissa (Calle de Santa María). El horizonte arcaico. IV Congreso Internacional de Estudios Fenicios y Púnicos (Cádiz, 1995).

Hachuel, E., y Marı, V. (1988): El Santuario de la lla Plana. Una propuesta de análisis. Trabajos del Museo Arqueológico de lbiza, 18. Ibiza.

Jodín, A. (1966): Mogador, comptoir phénicien du Maroc Atlantique. Études et Travaux d'Archéologie Marocaine, t. Il. Pabat.

JoNCHERAY, J.P. (1975): L'epave $C$ de la Chrétienne. C.A.S. Supplement 1. Frejus.

JuAN, J. (1988): Epigrafía romana de Ebusus. Trabajos del Museo Arqueológico de lbiza, 20. Ibiza.

Judas, A. (1859): Sur quelques médailies puniques d'îles de la Mediterranée. Revue Archéologique, $\mathrm{XV}$.

JuLLY, J. J. (1983): Présence Phénico-punique en Languedoc Méditerranéen et en Catalogne. Atti del I Congresso Internazionale di Studi Fenici e Punici, vol. III, págs. 805-814. Roma.

LóPEZ, A., y FIERRO, X. (1988): Darreres intervencions a l'assentament ibèric i la vil.la romana de Darró (Vilanova i la Geltrú, Garraf). Tribuna d'Arqueologia 1987-1988. págs. 53-68. Departament de Cultura de la Generalitat de Catalunya. Barcelona.

LóPEZ, A., y FIERRO, J. (1994): Un horno con ánforas de tipo púnico-ebusitano hallado en Darró (Vilanova i la Geltrú, Barcelona), en El mundo púnico. Historia, Sociedad y Cultura (Cartagena, 17-19 de noviembre de 1990), págs. 443-463. Murcia. 
LOPEZ CASTRO, J.L. (1991 a): El imperialismo cartaginés y las ciudades fenicias de la Península Ibérica entre los siglos vi-1Il a.C. Studi di Egittologia e di Antichità Puniche 9, págs. 87-107. Pisa.

López CASTro, J.L. (1991 b): Cartago y la Península Ibérica: Imperialismo o hegemonía? La caída de Tiro y el auge de Cartago. V Jornadas de Arqueología Fenicio-Púnica (lbiza, 1990).Trabajos del Museo Arqueológico de Ibiza. n²5, págs. 73-84. Ibiza.

López CAStRo, J.L. (1992 a): La colonización fenicia en la Península lbérica: 100 años de investigación. Actas del Seminario La colonización fenicia en el sur de la Península lbérica: 100 años de investigación. Centenario del inicio de las excavaciones de Luis Siret en Villaricos. (Almería, 5-7 de Junio de 1990). Colección Humanidades, 5, págs. 11-79. Instituto de Estudios Almerienses. Maracena (Granada).

López CASTRo, J.L. (1992 b): El concepto de romanización y los fenicios en la Hispania republicana. Problemas historiográficos. Actas del Seminario La colonización fenicia en el sur de la Península lbérica: 100 años de investigación. Centenario del inicio de las excavaciones de Luis Siret en Villaricos. (Almería, 5-7 de Junio de 1990). Colección Humanidades, 5, págs. 151-170. Instituto de Estudios Almerienses. Maracena (Granada).

LÓPEz CASTRO, J.L. (1992 c): Los libiofenicios: Una colonización agrícola cartaginesa en el sur de la Península Ibérica. Rivista di Studi Fenici vol. XX, 1, págs. 47-65. Consiglio Nazionale delle Ricerche. Roma.

López Castro, J.L. (1995): Hispania Poena. Los fenicios en la Hispania romana (206 a.C.-96 d.C.). Ed. Crítica. Barcelona.

López CASTRO, J.L.; SAN MARtín, G., y Escoriza, T. (1987-88): La colonización fenicia en el estuario del Almanzora. El asentamiento de Cabecico de Parra en Almizaraque (Cuevas de Almanzora, Almería). Cuadernos de Prehistoria de la Universidad de Granada 12-13, págs. 157-169. Granada.

Maluquer, J. (1969): Los fenicios en Cataluña. Tartessos. V Symposium Internacional de Prehistoria Peninsular (Jerez, 1968) págs. 241-250. Barcelona.

MANGAS, J. (1989): La municipalización flavia en Hispania. Aspectos de la colonización y municipalización de Hispania, págs. 153-172. Museo Nacional de Arte Romano. A.A. del Museo. Mérida.

Mangas, J. et alii (1982): España romana (218 a. de J.C.-414 de J.C.). Vol. II. La sociedad, el derecho, la cultura. Historia de España fundada por Ramón Menéndez Pidal. Ed. Espasa Calpe. Madrid.

MASCORT, M.T.; SANMARTI, J., y SANTACANA, J. (1991): El jaciment protohistòric d'Aldovesta (Benifallet) i el comerç fenici arcaic a la Catalunya meridional. Publicacions de la Diputació de Tarragona.

Mayet, F. (1975): Les céramiques à parois fines dans la Péninsule lbérique. Casa de Velázquez. Paris.

MESADO, N. (1974): Vinarragell (Burriana, Castellón). Trabajos Varios del S.I.P., 46. Valencia.

Miguélez, C. (1989): El vidrio romano en el Museo del Puig des Molins. Trabajos del Museo Arqueológico de lbiza, 21. Ibiza.

Moscati, S. (1989): L'ancora di argento. Colonie e commerci fenici tra Oriente e Occidente. Arte Storia Archeologia 2. Ed. Jaca Book Spa. Milano.

Moscatı, S. (1994): La funzione di Ibiza. Rivistá di Studi Fenici vol. XII, 1, págs. 51-56. Consiglio Nazionale delle Ricerche. Roma.

RAMÓN, J. (1981 a): Sobre els orígens de la colonia tenícia d'Eivissa. Rev. Eivissa no 12, págs. 224-31. Eivissa.

RAMÓN, J. (1981 b): Algunas formas cerámicas ebusitanas arcaicas y su conexion con las formas púnicas del Mediterráneo central. Informació Arqueològica no 36-37, maig-desembre, págs. 162-170. Barcelona.

RAMÓN, J. (1981 c): La producción anfórica púnico-ebusitana. Delegación del Ministerio de Cultura. lbiza.

RAMÓN, J. (1982 a): L’època fenicio-púnica i la seva trascendència en la història antiga d'Eivissa. Cuatro Conferencias del "Congrés de Cultura Pitiüsa». Ibiza.

RAmón, J. (1982 b): Cuestiones de comercio arcaico: frascos de aceite perfumado en el Mediterráneo central y occidental. Ampurias 44, págs. 17-41. Barcelona

RAMÓN, J. (1982 c): Es Cuieram 1907-1982: 75 años de investigación. Delegación del Ministerio de Cultura. Ibiza.

RAMÓN, J. (1983): Cuatro elementos cerámicos arcaicos de importación encontrados en Ibiza. Informació Arqueológica n 40, Gener-Juny, págs. 111-120. Barcelona. 
Ramón, J. (1984): L'assentament rural púnico-romà de Ses Païses de Cala d'Hort (Can Sorà) a Sant Josep (Eivissa). Eivissa.

Ramón, J. (1985 a): Guia Històrico-Arqueològica. Els monuments antics de les llies Pitiüses. Eivissa.

RAMÓN, J. (1985 b): Les anforetes Eb. 77 i algunes formes connexes de la producció ceràmica púnico-ebusitana tardana. Rev. Eivissa nos $15-16$, págs. 52-58. Eivissa.

RAMÓN, J. (1985 c): Es Cuieram. 1981. Noticiero Arqueológico Hispano, 20, págs. 225-253. Ministerio de Cultura. Madrid.

Ramón, J. (1986): Exportación en Occidente de un tipo ovoide de ánfora fenicio-púnica en época arcaica. Cuadernos de Prehistoria y Arqueología Castellonenses n 12, págs. 97-122. Castellón.

Ramón, J. (1987-88): El recinto púnico del Cap des Llibrell (lbiza). Saguntum, 21, págs. 265-293. Valencia.

Ramón, J. (1991 a): Las ánforas púnicas de Ibiza. Trabajos del Museo Arqueológico de lbiza, 23. Ibiza.

RAMón, J. (1991 b): El yacimiento fenicio de Sa Caleta. I-IV Jornadas de Arqueología FenicioPúnica (lbiza, 1986-1989). Trabajos del Museo Arqueológico de Ibiza, 24. Ibiza.

RAmón, J. (1992): La colonización arcaica de lbiza: Mecánica y proceso. La Prehistòria de les Illes de la Mediterrània Occidental. X Jornades d'Estudis Històrics Locals, págs. 453-478. Palma de Mallorca

Ramón, J. (1994): El nacimiento de la ciudad fenicia en la bahía de lbiza. El mundo púnico. Historia, Sociedad y Cultura (Cartagena, 17-19 de noviembre de 1990), págs. 325-367. Murcia.

Ramón, J. (1995 a): Las ánforas fencio-púnicas del Mediterráneo Central y Occidental. Col'lecció Instrumenta, 2. Universitat de Barcelona.

Ramón, J. (1995 b): Ses Païsses de cala d'Hort, un establiment rural d'època antiga al sud-oest d'Eivissa. Quaderns d'Arqueologia Pitiüsa, 1 (2a edició actualitzada i ampliada). Consell Insular d'Eivissa i Formentera. Eivissa.

Ramón, J. (1996): Las relaciones de Eivissa en época fenicia con las comunidades del Bronce Final y Hierro Antiguo de Catalunya, en ROVIRA, J. (Ed.): Models d'ocupació, transformació $i$ explotació del territori entre el 1600 i el 500 a.n.e. a la Catalunya Meridional $i$ zones limítrofes de la depressió de l'Ebre (Taules Rodones d'Arqueologia, Sant Feliu de Codines). Gala 3-5 (1994-1996), págs. 399-422.

RAMÓN, J. et alii (1981): Un taller de ceràmica d'època tardo-púnica a Can Rova de Baix, Sant Arioni de Portmany (Eivissa). Fonaments $n^{\circ} 3$, págs. 215-259. Barcelona.

Ripollés, P.P. (1982): La circulación monetaria en la Tarraconense mediterránea. S.I.P. Série de Trabajos Varios $\mathrm{n}^{\circ} 77$. Valencia.

ROMÁN Y CALVET, J. (1906): Los nombres é Importancia Arqueológica de las Islas Pythiusas. Barcelona.

Ruiz DE ARBULO, J. (1990): Rutas marítimas y colonizaciones en la Península lbérica. Una aproximación náutica a algunos problemas. Itálica 18, págs. 79-115. Cuadernos de Trabajo de la Escuela Española de Historia y Arqueología en Roma. Madrid-Roma.

SÁNCHEZ, C. (1981): La cerámica ática de Ibiza en el Museo Arqueológico Nacional. Trabajos de Prehistoria, 38, págs. 281-311. Madrid.

SANCHEZ, C. (1985): Algunas observaciones sobre la cerámica ática de lbiza. Ceràmiques gregues i helenístiques a la Península Ibèrica. Monografies Emporitanes, VII, págs. 83-85. Barcelona.

Sanmartí, J. (1991): El comercio tenicio y púnico en Cataluña. I-IV Jornadas de Arqueología Fenicio-Púnica (lbiza 1986-89). Trabajos del Museo Arqueológico de lbiza 24, págs. 119-136. Ibiza.

SCHULZ, H.D. (1997): Estratigrafía y líneas costeras durante el Holoceno en la isla de Ibiza. En Prospecciones Geo-arqueológicas en las costas de Ibiza. Trabajos del Museo Arqueológico de Ibiza, 38, págs. 11-31. Ibiza. (La versión alemana se publicó en 1993 en Madrider Mitteilungen, 34).

Schubart, H. (1982): Asentamientos fenicios en la costa meridional de la Península lbérica. Huelva Arqueológica, VI, págs. 71-99. Huelva.

ScHUBART, H. (1983): Morro de Mezquitilla. Vorbericht über die Grabungskampagne 1982 auf dem Siedlungshügel an der Algarrobo-Mündung. Madrider Mitteilungen, 24, págs. 104-131.

SOLÁ SOLÉ, J. M. (1951-52): La plaquette en bronze d'lbiza. Semitica, IV, págs. 24-31. París.

TAvares, A.A. (dir.) et alii (1993): Os Fenícios no Território Português. Estudos Orientais IV.Instituto Oriental. Lisboa. 
TopP, C.; Fernández, J.H. y Plantalamor, L. (1979): Recent archaeological activities in Ibiza and Formentera. Bulletin Institute of Archaeology, 16, págs. 215-231. University of London. London. TríAS, G. (1968): Cerámicas griegas de la Península lbérica.2 vols. Valencia.

ULRE!CH, H. et alii (1990): Cerro del Prado. Die Ausgrabungen 1989 im Schutthang der Phönizischen Ansiedlung an der Guadarranque-Mündung. Madrider Mitteilungen, 31, págs. 194-250.

Vullemot, G. (1965): Reconnaissances aux Échelles Puniques d'Oranie. Autun

Wagner, C.G. (1983): Fenicios y cartagineses en la Peninsula lbérica: Ensayo de interpretación fundamentado en un análisis de los factores internos. Tesis doctoral reprografiada (Universidad Complutense, 1981). Madrid.

WAGNER, C.G. (1984): El comercio púnico en el Mediterráneo a la luz de una nueva interpretación de los tratados concluidos entre Cartago y Roma. Memorias de Historia Antigua VI, págs. 211224. Universidad de Oviedo.

WAGNER, C.G. (1986): Cartago y Occidente. Una revisión crítica de la evidencia literaria y arqueológica. In Memoriam Agustín Díaz Toledo, págs. 437-460. Almería.

WAGNER, C.G. (1989): The Carthaginians in ancient Spain. From Administrative Trade to Territorial Annexation, en Devijuer, H. \& Lipinski, E. (eds.): Punic Wars (Antwerp, 23-26 November 1988). Studia Phoenicia $X$ (= Orientalia Lovaniensia Analecta 33), págs. 145-156. Leuven.

WAGNER, C.G. (1994): El auge de Cartago (s. VI-IV) y su manifestación en la Península Ibérica. Cartago, Gadir, Ebusus y la influencia púnica en los territorios hispanos. VIII Jornadas de Arqueología Fenicio-Púnica (Ibiza, 1993). Trabajos del Museo Arqueológico de lbiza, 33, págs. 7-22. Ibiza.

WAGNER, C.G., y AlyAR, J. (1989): Fenicios en Occidente: La colonización agricola. Rivista di Studi Fenici XVII,1, págs. 61-102. Consiglio Nazionale delle Ricerche. Roma.

WHITAKER, C.R. (1978): Carthaginian imperialism in the fifth and fourth centuries. Imperialism in the Ancient World, págs. 59-90. Cambridge University Press. Cambridge. 